\title{
Volatility, CORRELATION AND TAILS FOR SYSTEMIC RISK MEASUREMENT
}

\author{
Christian T. Brownlees* Robert Engle*
}

This Draft: May 2011

\begin{abstract}
In this paper we propose an empirical methodology to measure systemic risk. Building up on Acharya et al. (2010), we think of the systemic risk of a financial institution as its contribution to the total capital shortfall of the financial system that can be expected in a future crisis. We propose a systemic risk measure (SRISK) that captures the expected capital shortage of a firm given its degree of leverage and Marginal Expected Shortfall (MES). MES is the expected loss an equity investor in a financial firm would experience if the overall market declined substantially. To construct MES predictions, we introduce a dynamic model for the market and firm returns. This bivariate process is characterized by time varying volatility and correlation, which in turn are estimated by the familiar TARCH and DCC. The innovation distribution of the system is left unspecified and we rely on flexible methods for inference, allowing for potential tail dependence in the shocks. The model is extrapolated to estimate the equity losses of a firm in a future crisis and consequently the capital shortage that would be experienced depending on the initial leverage. The empirical application on a set of top US financial firms finds that the methodology provides useful rankings of systemically risky firms at various stages of the financial crisis. One year and a half before the Lehman bankruptcy, eight companies out of the SRISK top ten turned out to be troubled institutions. Results also highlight the deterioration of the capitalization of the financial system starting from January 2007 and that as of July 2010 the financial system does not appear fully recovered.
\end{abstract}

Keywords: Systemic Risk, Volatility, Correlations, Tails, Forecasting.

JEL classification: C22, C23, C53.

\footnotetext{
*Department of Finance, Stern School of Business, New York University, e-mail: ctbestern.nyu.edu, rengle@stern.nyu.edu. Systemic risk analysis results are published Vlab (http: //vlab. stern. nyu.edu/).

Acknowledgments. We are grateful for comments to Viral Acharya, Gianpiero Aielli, Matteo Barigozzi, Giuseppe Corvasce, Farhang Farazmand, Lasse Pedersen, Thomas Philoppon, Matthew Richardson, David Veredas, seminar participants at the ECARES seminar series and conference participants at the conference "Volatility and Systemic Risk" New York, April 16, 2010; "Fourth CIREQ Time Series Conference”, Montréal, May 14-15, 2010; “The Society for Financial Econometrics Third Conference”, Melbourne, Australia, 16-18 June, 2010. All mistakes are ours.
} 


\section{Introduction}

The Great Recession of 2007/2009 has motivated market participants, academics and regulators to better understand systemic risk. A useful definition of systemic risk by Federal Reserve Governor Daniel Tarullo, is

"Financial institutions are systemically important if the failure of the firm to meet its obligations to creditors and customers would have significant adverse consequences for the financial system and the broader economy."

In this definition, it is the failure of a systemically important firm to meet obligations that is the cause of systemic distress. Thus, measures of systemic risk are associated with firm bankruptcies or near bankruptcies which are inevitable consequences of a decline in equity valuations for highly levered firms.

This idea is further developed in the theoretical analysis of Acharya et al. (2010). A financial firm is unable to function when the value of its equity falls to a sufficiently small fraction of its outstanding liabilities. In good times, such a firm is likely be acquired, may be able to raise new capital or may face an orderly bankruptcy. If this capital shortage occurs just when the financial sector is already financially constrained, then the government faces the question of whether to rescue the firm with taxpayer money as other avenues are no longer available. Such a capital shortage is damaging to the real economy as the failure of this firm will have repercussions throughout the financial and real sectors. Consequently a firm is systemically risky if it is likely to face a large capital shortfall just when the financial sector itself is under distress.

The goal of this paper is to propose an empirical methodology to measure capital shortage in order to produce a systemic risk index for an individual firm. The capital shortfall of a firm depends on its degree of leverage and the equity losses that would result from such a crisis. While the degree of leverage can be measured, the equity losses in a crisis must be predicted. We predict them with the Marginal Expected Shortfall (MES), the expected equity 
loss of a firm when the overall market declines by a certain amount over a given period. The capital shortfall of a firm in a crisis computed using leverage and MES is what determines our Systemic Risk index (SRISK). The companies with the highest SRISK are the companies that contribute the most to the market undercapitalization in a crisis and are therefore the most systemically risky firms. Conceptually this calculation is like the stress tests that are regularly applied to financial firms, however here it is done with only publicly available information and is quick and inexpensive.

In this work, we begin by reviewing the key elements of the Acharya et al. (2010) framework and introduce the SRISK index. In order to construct the MES predictions needed for the calculation of the index, we propose a conditionally heteroskedastic bivariate model for market and firm equity return dynamics. This model characterizes the behaviour of the returns in terms of time varying volatility, correlation and tails. The specification does not make specific distributional assumptions on the innovation term of the process. A multi step modeling approach based on GARCH and DCC (Engle (2002b), Engle (2009)) is used to fit volatility and correlations. Inference on the innovation term is based on flexible methods and allow for potential nonlinear dependence in the shocks. The model is used to construct one and multi-period ahead MES forecasts, which we name, respectively, short and long run MES. The short and long run MES are defined, respectively, conditional on a $2 \%$ market drop over one day and $40 \%$ market drop over six months. In the short run case, predictions can be easily constructed using volatility, correlation predictions and nonparametric tail expectation estimators (Scaillet (2005)). Long run MES forecasts cannot be obtained in closed form but simulation based methods yeld such forecasts. The long run forecasts are the ones we use for construction of the SRISK index.

The proposed methodology is applied to analyse the systemic risk contribution of a sample of 94 top U.S. Financial firms between July 2000 and July 2010. Financial firms are grouped in 4 categories: Depositories, Insurance, Broker-Dealers and a residual category labelled Others which also contains non depositary institutions and real estate related firms. 
We begin by using our GARCH/DCC/Nonparametric approach to study the in sample dynamics of the panel of financial firms. We then carry out two different forecasting exercises. We first perform a short term MES forecasting exercise and use different criteria to measure predictive ability. We then engage a long run MES and SRISK forecasting exercise where we examine the rankings of systemically risky institution produced at various stages of the crisis as well as the dynamics of the aggregate SRISK in the sample.

The model implies that time varying firm volatility and correlation with the market are the most important determinants of MES. The more volatile a firm and the less diversified with respect to the market it is, the higher the MES. The time series analysis reveals that the level of MES during the financial crisis is extreme by historical standards. However, the MES industry group rankings have been stable in time, with Broker-Dealers and the Other sectors being the most exposed and, indeed, these sectors turned out to be the most levered and systemically risky during the financial crisis. The short term MES forecasting application shows that our MES predictions are able to perform well relative to simple benchmarks and produce good rank forecasts of the firms with bigger downside exposure. The long term MES forecasting results show that SRISK delivers useful rankings of systemically risky firms at various stages of the financial crisis. One year and a half before the Lehman bankruptcy, eight companies out of the SRISK top ten turned out to be troubled institutions. Results also document the deterioration of the financial system capitalization starting from July 2007 and that as of July 2010 the financial system does not appear fully recovered.

Our works relates to a growing number of contributions on the analysis of the financial crisis and the measurement of systemic risk. A current challenge in this field of research is that there is no widespread agreement on how systemic risk ought to be defined and, consequently, the measures being proposed have some degree of heterogeneity. The CoVaR of Adrian and Brunnermeier (2009) is one of the early proposal of the literature that has received notable attention. They relate systemic risk to the VaR of the market conditionally on an individual institution being under distress. Hautsch et al. (2010) define systemic risk as the time 
varying contribution of the firm VaR on the VaR of the market. Similarly, Manganelli et al. (2010) analyse spillover effects between the VaR of a financial institutions and the market. Billio et al. (2010) propose systemic risk indices based on Principal Component analysis and Granger-causality tests. Schwaab et al. (2011) introduce coincident risk measures and early warning indicators for financial distress which are extracted from macro and credit risk data. Contributions that relate to this area of research also include Allen et al. (2010), which assess the predictive power of a aggregate systemic risk measures in predicting future downturns and Brownlees (2011), which proposes a model to relate financial firms' dynamics to their characteristics. The methodology developed in this work relates to the literature on volatility and correlation modeling using, respectively, GARCH and DCC models. A detailed glossary of the ARCH universe can be found in Bollerslev (2008). The DCC approach for correlations has been introduced by Engle (2002a) and recently surveyed in Engle (2009). Contributions in this area include Engle and Sheppard (2001), Aielli (2006) and Engle et al. (2009). Dynamic models for Value-at-Risk and Expected Shortfall have been developed in Engle and Manganelli (2004) and Taylor (2008). Finally, the MES concept has been around the actuarial literature for quite same time under the name of conditional tail expectations (?). Nonparametric approaches to measures such expectations have been developed in Scaillet (2005),

The rest of the paper is organized as follows. Section 2 introduces the Acharya et al. (2010) framework and introduces the SRISK index. Section 3 describes the econometric methodology used to in this work to estimate MES. Section 4 illustrates the empirical application on a set of top U.S. financial firms. Concluding remarks follow in Section 5.

\section{Measuring Systemic Risk}

Acharya et al. (2010) develop a two period model where a financial institution $i$ chooses in period 0 how much capital to raise from risky debt, $f_{i}$, guaranteed debt, $g_{i}$, and initial capital, 
$w_{i}$. This is then invested in $J$ assets by taking exposures $x_{i 1}, \ldots, x_{i J}$. The risky debt is priced at a discount rate $b_{0}$ and the guaranteed debt is for simplicity priced at par. In period 1 , the exposures pay total return $r_{1}, \ldots, r_{J}$ and the debt must be repaid at face value. Because of bankruptcy costs and costs of capital shortage in general, there may be additional costs in period 1 . Thus the budget constraint in period 0 is

$$
w_{i 0}+f_{i 0} b_{0}+g_{i 0}=\sum_{j=1}^{J} x_{i j} .
$$

There may be regulatory capital requirements that would further restrict investment; if, for example this firm were required to hold a fraction $k$ of its assets as tier one capital, then

$$
w_{i 0} \geq \frac{k}{1-k}\left(g_{i 0}+b_{0} f_{i 0}\right)
$$

In period 1 the net worth of the institution is

$$
w_{i 1}=\sum_{j=1}^{J} x_{i j} r_{j}-g_{i 0}-f_{i 0}-\phi
$$

where $\phi$ is the cost of distress which could be bankruptcy or it could be the failure to carry out plans because of capital shortage. In general it will be a function of the state variables. If a prudential ratio of asset value to equity is $k$, then the firm's capital buffer in period 1 is

$$
k\left(f_{i 0}+g_{i 0}+w_{i 1}\right)-w_{i 1}
$$

and when this value is positive the firm is said to experience a capital shortage.

The key assumption of Acharya et al. (2010) is that capital shortages of an individual firm impose external costs on the real economy when they occur during a period of distress for the whole system. These costs are first of all costs to taxpayers who offer the guarantee in $g_{i}$. They however also include externalities that are particularly severe when the entire financial 
sector is capital constrained. When the economy is in a downturn, the bankruptcy of a firm cannot be absorbed by a stronger competitor and obligations will spread throughout both the financial and real economy as the natural functions of the financial sector will be curtailed. When the system is undercapitalized, it will no longer supply credit for ordinary everyday business and the economy will grind to a halt. Thus the shortage of capital is dangerous for one firm and for its bondholders, but it is dangerous for the economy if it occurs just when the rest of the sector is undercapitalized.

Thus it is of interest to measure what the capital shortfall would be for each firm in a crisis. To do this we estimate the equity losses that can be expected for each firm in a crisis and then compute the consequent capital shortfall. We define a crisis as of fall of the market index below a certain threshold $C$, which we call for short "systemic event". The expected capital shortfall $\mathrm{CS}_{i 0}$ in period 1 is estimated in period 0 to be

$$
\begin{aligned}
\mathrm{CS}_{i 0} & =\mathrm{E}_{0}\left(k\left(f_{i 0}+g_{i 0}+w_{i 1}\right)-w_{i 1} \mid \text { Crisis }\right) \\
& =k\left(f_{i 0}+g_{i 0}\right)-(1-k) \mathrm{E}_{0}\left(w_{i 1} \mid \text { Crisis }\right) \\
& =k\left(f_{i 0}+g_{i 0}\right)-(1-k) w_{i 0} \mathrm{E}_{0}\left(R_{i 1} \mid R_{m 1}<C\right) \\
& =k\left(f_{i 0}+g_{i 0}\right)-(1-k) w_{i 0} \mathrm{MES}_{i 0}
\end{aligned}
$$

where $R_{i 1}$ and $R_{m 1}$ are the firm and market (arithmetic) returns in period 1 and MES stands for Marginal Expected Shortfall, the tail expectation of the firm return conditional on the market being in its left tail (Scaillet $(2005))$. The firms with the largest capital shortfall are the greatest contributors to the crisis and are the institutions considered as most systemically risky. We define the systemic risk index of institution $i$ as

$$
\mathrm{SRISK}_{i}=\min \left(0, \mathrm{CS}_{i 0}\right)
$$


and its percentage version as

$$
\operatorname{SRISK} \%_{i}=\mathrm{SRISK}_{i} / \sum_{i} \mathrm{SRISK}_{i}
$$

Hence, the SRISK\% index measures the portion of the total expected system capital shortfall in a crisis that is due to firm $i$.

In this framework, systemic risk arises because of the combination of different ingredients. An increase in the size of the firm, keeping the leverage ratio constant, increases systemic risk in that it makes the capital shortage potentially wider. An increase in debt also has positive impact on systemic risk in that this increases the capital requirement of the firm. Finally, a high downside exposure of the firm to systematic shocks in the economy contributes positively to an increase of systemic risk.

An appealing feature of the SRISK index is that it can be constructed using publicly available data, making the index widely applicable and relatively inexpensive to implement.

\section{Econometric Methodology}

The computation of the systemic risk indices requires knowledge of the debt, equity and MES of each firm. While debt and equity values are readily available, the estimation of the MES requires the introduction of appropriate time series techniques. In this work we are interested in estimating the capital shortfall over a potentially long time period like, say, a quarter or six months. Hence, we need time series methods able to deliver estimates of MES over long horizons. Many strategies can be devised to attack this problem. In this work we tackle the issue by specifying a bivariate conditionally heteroskedastic model to characterize the dynamics of the daily firm and market returns. Once the model is estimated, the process can be easily extrapolated to produce the MES predictions of interest.

Let $r_{i t}$ and $r_{m t}$ denote respectively firm's $i$ and the market log return on day $t$. Our 
approach starts from a description of the bivariate process of the firm and market returns:

$$
\begin{aligned}
r_{m t} & =\sigma_{m t} \epsilon_{m t} \\
r_{i t} & =\sigma_{i t} \rho_{i t} \epsilon_{m t}+\sigma_{i t} \sqrt{1-\rho_{i t}^{2}} \xi_{i t} \\
\left(\epsilon_{m t}, \xi_{i t}\right) & \sim F
\end{aligned}
$$

where the shocks $\left(\epsilon_{m t}, \xi_{i t}\right)$ are independent and identically distributed over time and have zero mean, unit variance and zero covariance. However they are not assumed to be independent. Indeed, there are important reasons to believe that extreme values of these disturbances could occur at the same time for systemically risky firms. When the market is in its tail, the firm disturbances may be even further in the tail if there is serious risk of default.

The stochastic specification is completed by a description of the two conditional standard deviations and the conditional correlation. These will be discussed in the next section but are familiar models of asymmetric GARCH and DCC. On the other hand, the distribution $F$ is left unspecified and we will adopt flexible nonparametric approach for inference.

The one period ahead MES can be straightforwardly expressed as a function of volatility, correlation and tail expectations of the standardised innovations distribution

$$
\begin{aligned}
\operatorname{MES}_{i t-1}^{1}(C)= & \mathrm{E}_{t-1}\left(r_{i t} \mid r_{m t}<C\right) \\
= & \sigma_{i t} \mathrm{E}_{t-1}\left(\epsilon_{i t} \mid \epsilon_{m t}<C / \sigma_{m t}\right) \\
= & \sigma_{i t} \mathrm{E}_{t-1}\left(\rho_{t} \epsilon_{m t}+\sqrt{1-\rho_{t}^{2}} \xi_{i t} \mid \epsilon_{m t}<C / \sigma_{m t}\right) \\
= & \sigma_{i t} \rho_{t} \mathrm{E}_{t-1}\left(\epsilon_{m t} \mid \epsilon_{m t}<C / \sigma_{m t}\right)+ \\
& \sigma_{i t} \sqrt{1-\rho_{t}^{2}} \mathrm{E}_{t-1}\left(\xi_{i t} \mid \epsilon_{m t}<C / \sigma_{m t}\right),
\end{aligned}
$$

and the conditional probability of a systemic event is

$$
\operatorname{PoS}_{t}^{1}(C)=P_{t-1}\left(r_{m t}<C\right)=P\left(\epsilon_{m t}<C / \sigma_{m t}\right)
$$


Some comments on the formulas in Equations (1) and (2) are in order under the assumption that the conditional correlation of the firm with the market is positive. Firstly MES is an increasing function of a firm's own volatility. Depending on whether correlation is high or low, the MES formula gives more weight to, respectively, either the tail expectation of the standardised market residual or the tail expectation of standardised idiosyncratic firm residual. The second term in Equation (1) arises because of the nonlinear dependence assumption between $\epsilon_{m t}$ and $\xi_{i t}$ and it would otherwise be zero if dependence was captured entirely by correlation. Secondly, MES relates to the systematic risk "beta" of the CAPM. If the data are generated by a one factor model then MES is equal to systematic risk times the Expected Shortfall of the market. Our approach however is more flexible in that it allows for time varying moments and focuses on the left tail. It is also important to stress the implication of the conditioning systemic event $C$. Typically, VaR and ES are expressed in conditional terms, that is the conditioning event is a quantile from the conditional return distribution. On the other hand, in this work the conditioning event is unconditional. Thus, while in the conventional approach the probability of observing the conditioning event is constant, in our framework such probability is time varying: the higher the volatility the higher the probability of observing a loss above a fixed threshold. Equation (1) has an approximation error due to the fact we are using log returns rather than arithmetic returns. In this work we do not add an adjustment term to the formula, but this has been worked out in Caporin and De Magistris (2010). In what follows we are going to call the 1 period ahead MES as "short term" and we are going to set the constant $C$ to a $2 \%$ market drop.

The multi-period ahead MES cannot be obtained in closed form and a nonparametric boostrap procedure is used to construct forecasts. The procedure works as follows. In order to produce the $h$ period ahead MES starting from day $t$, on day $t-1$ we simulate $S$ paths of 
length $h$

$$
\left\{\begin{array}{c}
r_{m t+\tau-1}^{s} \\
r_{i t+\tau-1}^{s}
\end{array}\right\}_{\tau=1}^{h} s=1, \ldots, S,
$$

drawing values from the model with current levels of volatility and correlations as starting conditions. The shocks for the path simulations are drawn from the system innovations distribution $F$

$$
\left(\epsilon_{m t+\tau-1}^{s}, \xi_{m t+\tau-1}^{s}\right)_{\tau=1}^{h} \sim F
$$

and are then "re-coloured" thorugh the DCC and GARCH filters. The multi period MES is calculated as the Monte Carlo average of the simulations,

$$
\mathrm{MES}_{i t-1}^{h}(C)=\frac{\sum_{s=1}^{S} R_{i t: t+h-1}^{s} I\left\{R_{m t: t+h-1}^{s}<C\right\}}{\sum_{s=1}^{S} I\left\{R_{m t: t+h-1}^{s}<C\right\}},
$$

where $R_{i t: t+h-1}^{s}$ denotes the $s$ simulated cumulative return of firm $i$ from period $t$ to period $t+h-1$, i.e.

$$
R_{i t: t+h-1}^{s}=\exp \left\{\sum_{\tau=1}^{h} r_{i t+\tau-1}^{s}\right\}-1,
$$

and similarly for the market return $R_{m t: t+h-1}^{s}$. Analogously, the multi-period probability of a crisis is given by

$$
\operatorname{PoS}_{t}^{h}(C)=P_{t}\left(R_{m t: t+h-1}<C\right)=\frac{1}{S} \sum_{s=1}^{S} I\left\{R_{m t: t+h-1}^{s}<C\right\} .
$$

This approach is close in spirit to what risk management practitioners call "scenario analysis", that is extrapolating the risk implied by the model conditionally on a stream of adverse outcomes. In what follows we are going to consider a 6 months period MES using a market drop $C$ of $40 \%$ and we are going to call this prediction long run MES. A useful feature of long run forecasts is that they partly counter the pro-cyclical nature of short term risk assessment. 
For instance, in a period of low short term MES, computing MES over a long horizon is going to include many simulated paths where the MES reverts to higher unconditional levels.

Different strategies can be employed to obtain estimates of MES at the horizons of interest. In this work we rely on a multi stage modeling approach which is inspired by the DCC (Engle (2002a), Engle (2009)). In the first step we model volatilities using GARCH models to obtain conditional volatility and standardised residuals. We then resort to a DCC specification to obtain conditional correlation and the standardised idiosyncratic firm residual. Finally, inference on the model innovations is based on the GARCH/DCC residuals. The appealing features of such a modelling paradigm are simplicity and flexibility. Estimation of a fully bivariate conditionally heteroskedastic model with nonlinear residual dependence for a large panel of assets (some of which are not too long) can be quite challenging. On the other hand our approach is much easier to implement and it allows for considerable flexibly in the specifications, by changing the different types of volatility (splines, high frequency based, etc.) and correlation (standard DCC, factor DCC, asymmetric, breaks in correlation, etc. ).

In what follows we make the follow modelling choices:

Volatility. In the wide universe of GARCH specifications, we pick the TARCH specification to model volatility (Rabemananjara and Zakoïan (1993), Glosten et al. (1993)). The evolution of the conditional variance dynamics in this model class is given by

$$
\begin{aligned}
\sigma_{m t}^{2} & =\omega_{m G}+\alpha_{m G} r_{m t-1}^{2}+\gamma_{m G} r_{m t-1}^{2} I_{m t-1}^{-}+\beta_{m G} \sigma_{m t-1}^{2} \\
\sigma_{i t}^{2} & =\omega_{i G}+\alpha_{i G} r_{i t-1}^{2}+\gamma_{i G} r_{i t-1}^{2} I_{i t-1}^{-}+\beta_{i G} \sigma_{i t-1}^{2}
\end{aligned}
$$

with $I_{i t}^{-}=r_{i t}<0$ and $I_{m t}^{-}=r_{m t}<0$. The main highlight of this specification is its ability to capture the so called leverage effect, that is the tendency of volatility to increase more with negative news rather than positive ones. This model is also successful from a forecasting standpoint and it turns out to be quite difficult to beat. We estimate the model using QML 
which guarantees consistent estimates of the model parameters as long as the conditional variance equation is correctly specified.

Correlations. We model time varying correlations using the DCC approach (Engle (2002a), Engle (2009)). Let $P_{t}$ denote the time varying correlation matrix of the market and firm return, that is, using matrix notation,

$$
\begin{aligned}
\operatorname{Var}_{t-1}\left(\begin{array}{c}
r_{i t} \\
r_{m t}
\end{array}\right) & =D_{t} P_{t} D_{t} \\
& =\left[\begin{array}{cc}
\sigma_{i t} & 0 \\
0 & \sigma_{m t}
\end{array}\right]\left[\begin{array}{cc}
1 & \rho_{t} \\
\rho_{t} & 1
\end{array}\right]\left[\begin{array}{cc}
\sigma_{i t} & 0 \\
0 & \sigma_{m t}
\end{array}\right]
\end{aligned}
$$

Rather than directly modeling the $P_{t}$ matrix, the DCC framework models the so-called pseudo correlation matrix $Q_{t}$, a positive definite matrix which is then mapped in a correlation matrix through the transformation

$$
P_{t}=\operatorname{diag}\left(Q_{t}\right)^{-1 / 2} Q_{t} \operatorname{diag}\left(Q_{t}\right)^{-1 / 2},
$$

where the $\operatorname{diag}(A)$ matrix operator denotes a matrix with the same elements of the $A$ matrix on the diagonal and zero otherwise. We formulate the pseudo correlation matrix $Q_{t}$ dynamics using the DCC formulation proposed in Aielli (2006) and Aielli (2009).

The basic (scalar) symmetric DCC specification is defined as

$$
Q_{t}=\left(1-\alpha_{C}-\beta_{C}\right) S+\alpha_{C} \epsilon_{t-1}^{*} \epsilon_{t-1}^{*^{\prime}}+\beta_{C} Q_{t-1}
$$

where $S$ is an intercept matrix and $\epsilon_{t}^{*}$ contains the rescaled standardised (or degarched) returns, that is $\epsilon_{t}^{*}=Q_{t-1}^{*} \epsilon_{t}$ with $Q_{t}^{*}=\operatorname{diag}\left(Q_{t}\right)^{1 / 2}$. The pseudo conditional correlation matrix $Q_{t}$ is thus an exponentially weighted moving average of past outer products of the rescaled 
standardised returns. Necessary and sufficient conditions for $Q_{t}$ to be positive definite are $\alpha_{C}>0, \beta_{C}>0, \alpha_{C}+\beta_{C}<1$ and the positive definiteness of the $S$ matrix. The rescaling device ensures that $\left\{\epsilon_{t}^{*}, Q_{t}\right\}$ is a MGARCH process (Ding and Engle (2001)) and, under the assumption of stationarity of the model $\left(\alpha_{C}+\beta_{C}<1\right)$, this implies that $S$ is the unconditional covariance matrix of $\epsilon_{t}^{*}$

$$
S=\mathrm{E}\left(\epsilon_{t}^{*} \epsilon_{t}^{*^{\prime}}\right)
$$

This property is useful for highly dimensional DCC estimation in that it justifies the use of the unconditional covariance matrix of the $\epsilon_{t}^{*}$ as a correlation targeting (Mezrich and Engle (1996)) estimator for $S$, that is

$$
\hat{S}=\frac{1}{n} \sum \epsilon_{t}^{*} \epsilon_{t}^{* \prime}
$$

which drastically reduces the number of parameter that need to be optimized to estimate the model. A slight complication of the $\hat{S}$ estimator is that it is based on the diagonal of the $Q_{t}$ matrix which in turns depends on the parameter values of the model. Hence, in the evaluation of the likelihood, for instance, the estimators have to be computed each time. Also note that the diagonal elements of $S$ are either known or can be computed without knowledge of the model parameters. The computation of the likelihood proceeds by first computing the diagonal of $Q_{t}$, evaluating the $\hat{S}$ matrix and finally computing the off diagonal elements of $Q_{t}$ and the likelihood of the model.

Tail Expectations for Short Term MES. To compute short term MES in Equation (1) we need to estimate of the tail expectations

$$
\mathrm{E}\left(\epsilon_{m t} \mid \epsilon_{m t}<\kappa\right) \quad \text { and } \quad \mathrm{E}\left(\xi_{i t} \mid \epsilon_{m t}<\kappa\right)
$$

These expectation can be simply estimated for a particular value of the variances $\left(\sigma_{m t}^{2}, \sigma_{i t}^{2}\right)$ and conditional correlation $\rho_{t}$ by simply looking at the average of the two residuals in all 
cases which satisfy the condition $\epsilon_{m t}<\kappa$. However, when $-\kappa$ is large, this estimator will be unstable as there are only a small number of observations. A nonparametric kernel estimation approach can be used to improved the efficiency of these simple estimators. Let

$$
K_{h}(t)=\int_{\infty}^{t / h} k(u) d u
$$

where $k(u)$ is a kernel function and $h$ is a positive bandwidth. Then

$$
\widehat{\mathrm{E}}_{h}\left(\epsilon_{m t} \mid \epsilon_{m t}<\kappa\right)=\frac{\sum_{i=1}^{n} \epsilon_{m t} K_{h}\left(\epsilon_{m t}-\kappa\right)}{\left(n \hat{p}_{h}\right)},
$$

and

$$
\widehat{\mathrm{E}}_{h}\left(\xi_{i t} \mid \epsilon_{m t}<\kappa\right)=\frac{\sum_{i=1}^{n} \xi_{i t} K_{h}\left(\epsilon_{m t}-\kappa\right)}{\left(n \hat{p}_{h}\right)}
$$

where

$$
\hat{p}_{h}=\frac{\sum_{i=1}^{n} K_{h}\left(\epsilon_{m t}-\kappa\right)}{n}
$$

An advantage of the nonparametric estimators defined in Equations (6) and (7) is that they are smooth functions of the cutoff point $\kappa$ which, in turns, deliver smooth estimates of short term MES as a function of $\kappa$.

Simulations for Long Term MES. To compute the long term MES of Equation (3), we need to draw samples from the innovation distribution $F$. The sampling strategy we adopt is to sample the estimated residuals of the model with replacement. A number of algorithmic shortcuts can be implemented to reduce substantially the computational burden of the long term MES computation in large panel of firms. The strategy we adopt is to simulate $S$ market paths and check which paths meet the systemic event condition. For each of these paths, we store the sequence of id's of the selected draws. Then, the simulation of the individual firm trajectories consists of constructing for each selected path the sequence of individual firm 


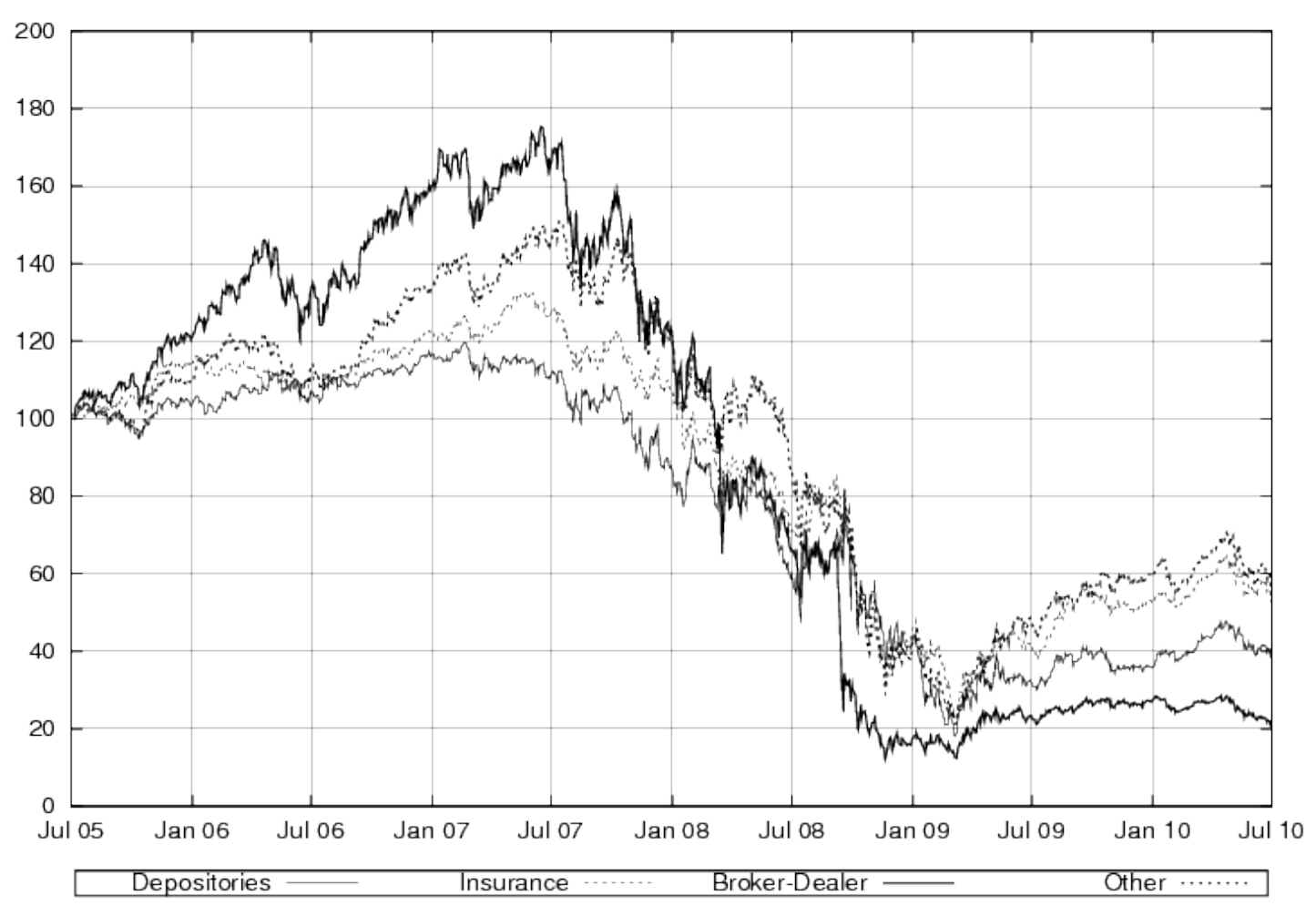

Figure 1: Cumulative average return by industry group.

shocks which correspond to those of the market. This speeds up the simulations in that it avoids having to simulate and select paths for each firm/market return pair in the panel.

\section{Empirical Analysis}

\subsection{Data}

We study the same panel of institutions studied in Acharya et al. (2010) between July 3, 2000 and June 30, 2010. The panel contains all U.S. financial firms with a market capitalization greater than 5 bln USD as of the end of June 2007 and it is unbalanced in that not all companies have continuously been trading during the sample period. We extract daily returns and market capitalization from CRSP and the quarterly book value of equity (ceqq) from COMPUSTAT. SIC codes are used to divide firms into 4 groups: Depositories (such as Bank of 


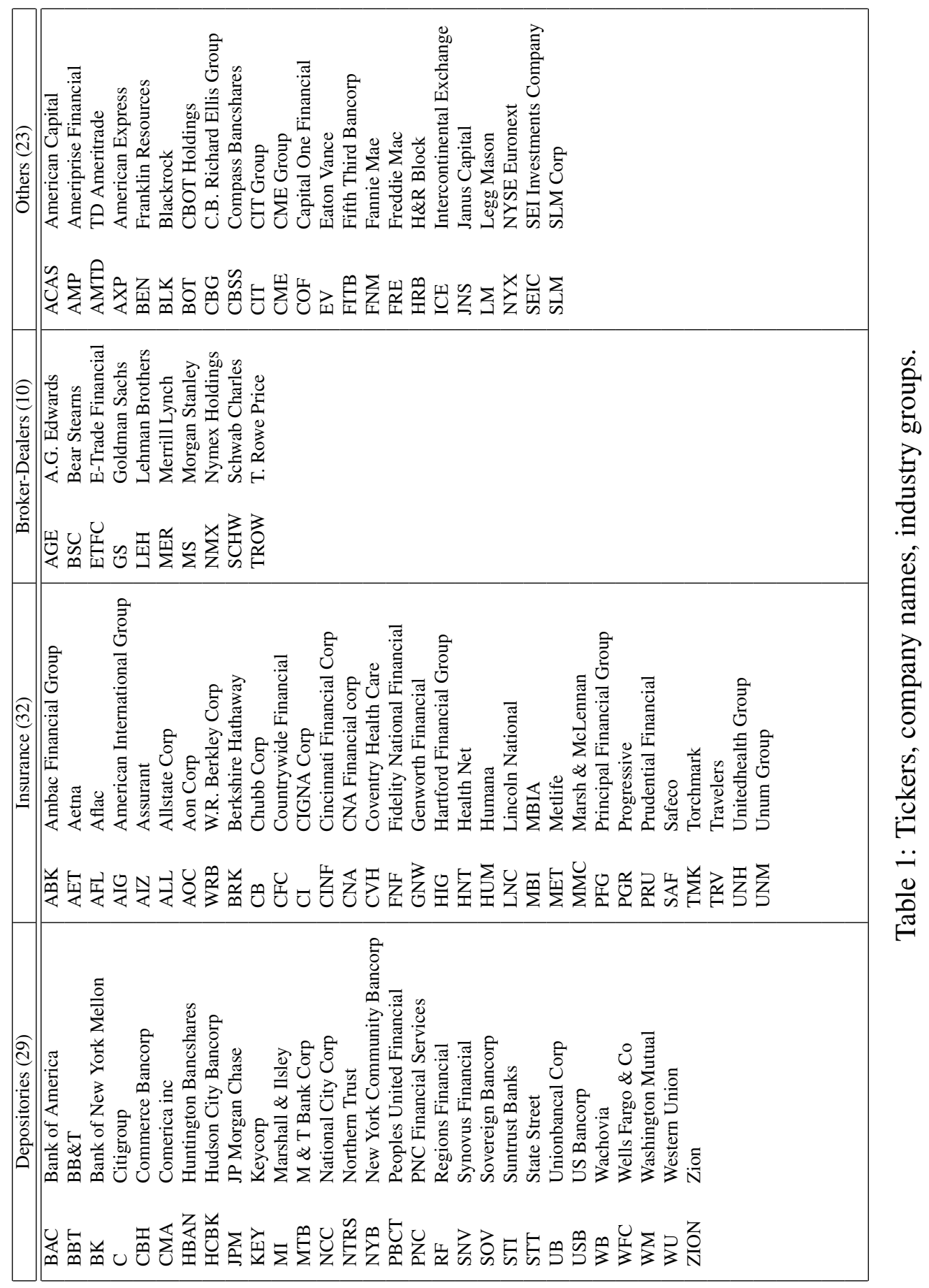




\begin{tabular}{|c|c|c|c|c|c|c|}
\hline & & Avg. Ret. & Vol. & Corr. & Beta & QLVG \\
\hline & \multicolumn{6}{|c|}{ Pre-Crisis (2005-07 to 2007-07) } \\
\hline \multirow[t]{3}{*}{ Depos } & $Q_{1}$ & 0.01 & 14.85 & 0.53 & 0.86 & 4.92 \\
\hline & Med. & 0.03 & 15.95 & 0.60 & 0.93 & 5.90 \\
\hline & $Q_{3}$ & 0.08 & 17.80 & 0.66 & 1.00 & 6.86 \\
\hline \multirow[t]{3}{*}{ Insur } & $Q_{1}$ & 0.06 & 15.56 & 0.36 & 0.76 & 2.45 \\
\hline & Med. & 0.12 & 18.10 & 0.50 & 0.83 & 3.08 \\
\hline & $Q_{3}$ & 0.17 & 24.88 & 0.57 & 1.00 & 6.83 \\
\hline \multirow[t]{3}{*}{ Bro-Deal } & $Q_{1}$ & 0.21 & 20.81 & 0.62 & 1.39 & 1.67 \\
\hline & Med. & 0.23 & 23.43 & 0.69 & 1.55 & 8.55 \\
\hline & $Q_{3}$ & 0.30 & 27.84 & 0.74 & 1.67 & 13.05 \\
\hline \multirow[t]{4}{*}{ Other } & $Q_{1}$ & 0.00 & 19.66 & 0.42 & 0.96 & 1.14 \\
\hline & Med. & 0.17 & 24.20 & 0.49 & 1.21 & 1.51 \\
\hline & $Q_{3}$ & 0.31 & 31.13 & 0.56 & 1.49 & 5.26 \\
\hline & \multicolumn{6}{|c|}{ Crisis (2007-07 to 2009-07) } \\
\hline \multirow[t]{3}{*}{ Depos } & $Q_{1}$ & -0.98 & 67.08 & 0.60 & 1.37 & 7.20 \\
\hline & Med. & -0.37 & 92.44 & 0.67 & 1.78 & 13.02 \\
\hline & $Q_{3}$ & -0.18 & 112.31 & 0.71 & 2.09 & 18.22 \\
\hline \multirow[t]{3}{*}{ Insur } & $Q_{1}$ & -0.58 & 55.57 & 0.56 & 0.99 & 2.40 \\
\hline & Med. & -0.37 & 68.86 & 0.65 & 1.33 & 4.19 \\
\hline & $Q_{3}$ & -0.24 & 105.06 & 0.73 & 2.11 & 19.60 \\
\hline \multirow[t]{3}{*}{ Bro-Deal } & $Q_{1}$ & -1.39 & 65.32 & 0.52 & 1.47 & 1.46 \\
\hline & Med. & -0.41 & 86.48 & 0.76 & 1.87 & 20.76 \\
\hline & $Q_{3}$ & -0.11 & 136.69 & 0.77 & 2.33 & 39.10 \\
\hline \multirow[t]{4}{*}{ Other } & $Q_{1}$ & -0.70 & 64.89 & 0.61 & 1.45 & 1.73 \\
\hline & Med. & -0.45 & 78.32 & 0.72 & 1.76 & 2.29 \\
\hline & $Q_{3}$ & -0.24 & 113.40 & 0.80 & 2.06 & 11.48 \\
\hline & \multicolumn{6}{|c|}{ Post-Crisis (2009-07 to 2010-07) } \\
\hline \multirow[t]{3}{*}{ Depos } & $Q_{1}$ & -0.10 & 32.33 & 0.58 & 1.17 & 7.31 \\
\hline & Med. & 0.24 & 37.18 & 0.64 & 1.38 & 10.84 \\
\hline & $Q_{3}$ & 0.38 & 52.62 & 0.69 & 1.62 & 15.93 \\
\hline \multirow[t]{3}{*}{ Insur } & $Q_{1}$ & 0.12 & 25.05 & 0.48 & 0.84 & 2.45 \\
\hline & Med. & 0.22 & 36.45 & 0.70 & 1.14 & 4.48 \\
\hline & $Q_{3}$ & 0.33 & 43.50 & 0.80 & 1.82 & 17.44 \\
\hline \multirow[t]{3}{*}{ Bro-Deal } & $Q_{1}$ & -0.21 & 33.00 & 0.61 & 1.12 & 3.36 \\
\hline & Med. & -0.14 & 34.14 & 0.66 & 1.40 & 10.41 \\
\hline & $Q_{3}$ & -0.07 & 42.10 & 0.76 & 1.56 & 18.44 \\
\hline \multirow[t]{3}{*}{ Other } & $Q_{1}$ & -0.11 & 32.48 & 0.64 & 1.15 & 1.73 \\
\hline & Med. & 0.04 & 37.96 & 0.71 & 1.43 & 2.24 \\
\hline & $Q_{3}$ & 0.40 & 47.08 & 0.79 & 1.76 & 7.16 \\
\hline
\end{tabular}

Table 2: Descriptive statistics.

America or JP Morgan Chase), Broker-Dealers (Goldman Sachs or Lehman Brothers), Insurance (AIG) and Others (non depositary institutions, real estate) (Freddie and Fannie). We make one exception to this rule, Goldman Sachs (GS) should have been classified within the Others group, but instead we put it with Brokers-Dealers. We also use the daily CRSP market value weighted index return as the market index return. The full list of tickers and company names divided by industry groups is reported in Table 1 .

It is important to give further details about the industry grouping. The Broker-Dealers group contains the top U.S. investment banks. Many of these companies were in severe 


\begin{tabular}{|ll|cccc|ccc|}
\hline & & vol & $\alpha_{V}$ & $\gamma_{V}$ & $\beta_{V}$ & cor & $\alpha_{C}$ & $\beta_{C}$ \\
\hline \hline Depos. & $Q_{1}$ & 32.21 & 0.02 & 0.08 & 0.87 & 0.55 & 0.03 & 0.89 \\
& Median & 36.92 & 0.04 & 0.10 & 0.91 & 0.62 & 0.04 & 0.93 \\
& $Q_{3}$ & 40.14 & 0.07 & 0.12 & 0.92 & 0.66 & 0.05 & 0.96 \\
\hline Insur. & $Q_{1}$ & 29.93 & 0.02 & 0.09 & 0.86 & 0.44 & 0.01 & 0.91 \\
& Median & 37.64 & 0.04 & 0.11 & 0.90 & 0.52 & 0.03 & 0.95 \\
& $Q_{3}$ & 44.12 & 0.05 & 0.13 & 0.92 & 0.58 & 0.05 & 0.98 \\
\hline Bro.-Deal. & $Q_{1}$ & 37.86 & 0.00 & 0.09 & 0.89 & 0.65 & 0.01 & 0.92 \\
& Median & 41.55 & 0.01 & 0.12 & 0.93 & 0.69 & 0.03 & 0.95 \\
& $Q_{3}$ & 45.99 & 0.03 & 0.22 & 0.95 & 0.73 & 0.04 & 0.97 \\
\hline Other & $Q_{1}$ & 36.03 & 0.02 & 0.07 & 0.87 & 0.47 & 0.01 & 0.92 \\
& $M e d i a n$ & 42.57 & 0.04 & 0.09 & 0.90 & 0.58 & 0.02 & 0.96 \\
& $Q_{3}$ & 49.84 & 0.05 & 0.11 & 0.92 & 0.65 & 0.04 & 0.98 \\
\hline
\end{tabular}

Table 3: TARCH and DCC estimation results.

distress in the crisis: Lehman Brothers (LEH) was liquidated, Bear Stearns (BNC) and Merrill Lynch (MER) sold, Goldman Sachs (GS) and Morgan Stanley (MS) became commercial banks switching to a more stringent regulatory regime. The residual group Others contains real estate badly hit by the crisis, like Freddie (FRE) and Fannie (FAN) which were placed into conservatorship. These institutions as of June 2007 were also large and highly leveraged and subject to looser regulations than the standard commercial banks which make up the Depositories group.

Figure 1 gives visual insights on the boom and bust of the financial sector. The figures show the cumulative average return by industry group over the full sample. Between July 2005 and June 2007 all financial groups had a steep growth, which is particularly strong for the Broker-Dealer group. Starting from July 2007, the fall of financials has been dramatic, with the biggest winners transforming into the biggest losers.

Table 2 reports descriptive statistics of the set of tickers divided by industry group over three subsamples (the pre-crisis, crisis and post-crisis). For each statistic the table reports the median, 1st and 3rd quartiles across each group. 


\subsection{Full Sample Estimation Results}

The methodology introduced in Section 3 is used to analyse our panel of large U.S. financial firms: We fit TARCH and DCC models for each firm in the panel over the whole sample but show time series plots in between 2005 and 2010 only.

Interestingly, the dynamics of the firms in the panel do not have a strong degree of heterogeneity. To see this, we report in Table 3 a summary of the estimation results from the full sample. For each asset class, the table shows selected quantiles of the parameter estimates of the TARCH (left side) and DCC (right side) models. The TARCH parameters do not fluctuate much within groups, with the only exception of intercept term which is on average higher for Broker-Dealers and Others. Also, the range of $\gamma$ coefficient capturing volatility asymmetry reaches larger values for Broker-Dealer signaling higher sensitivy to large volatility surges in case of a drop of the stock. Over ally, the point estimates are in line with the typical GARCH estimates, with slightly higher $\alpha$ 's and $\gamma$ 's and lower $\beta$ 's implying a higher level of unconditional kurtosis. Turning to the DCC, parameters are again close to the typical set of estimates. Intercept aside, parameters are similar across groups. Broker-Dealers have the highest level of unconditional correlation, followed by the Others, Insurance and Depository institutions.

The time series industry group averages of volatility, correlation and short term MES provide interesting insights on the dynamics of risk before, during and after the crisis.

Figure 2 displays the annualised volatility series averages by industry group. These plots are all dominated by the surge in volatility at the peak of the crisis, which is so high it makes it difficult to see other relevant periods of distress. Over all, all groups exhibit a similar time series pattern which can be associated with the general level of volatility in the economy. The pre crisis period is characterised by extremely low levels of volatility. Starting from July 2007 in the crisis period however, volatility gradually surges as the financial crisis unwraps and in December 2008 it peaks to the highest levels ever measured over the last 20 years of data. Volatility then slowly decays and by March 2009, in conjunction with 

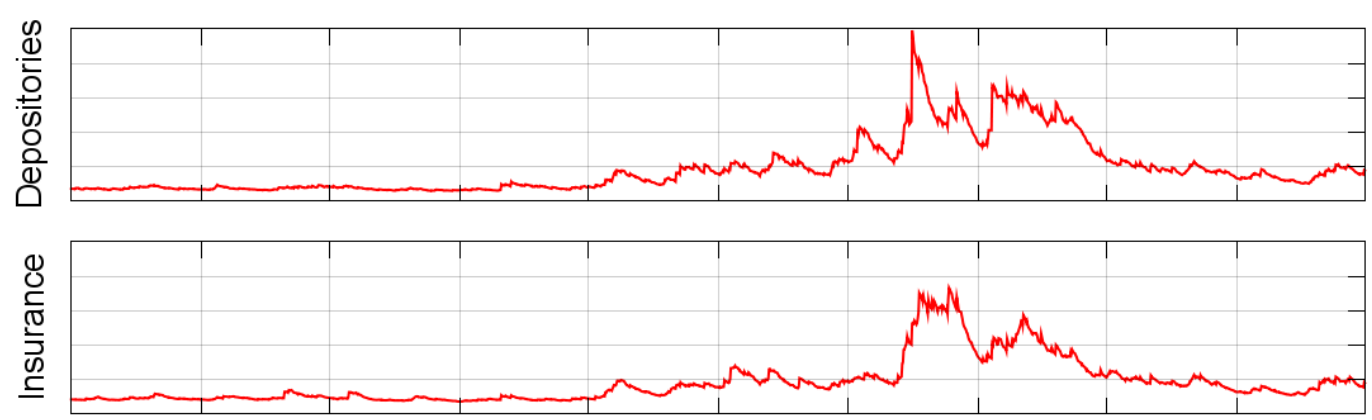

$250 \%$ $200 \%$ $150 \%$ $100 \%$ $50 \%$

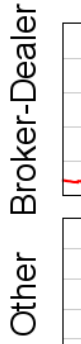
\begin{tabular}{l|l|l|l|l||l|l|l|l|l|l|}
$250 \%$ & \\
2 & $200 \%$
\end{tabular} - $150 \%$ (WM $100 \%$ 50\%

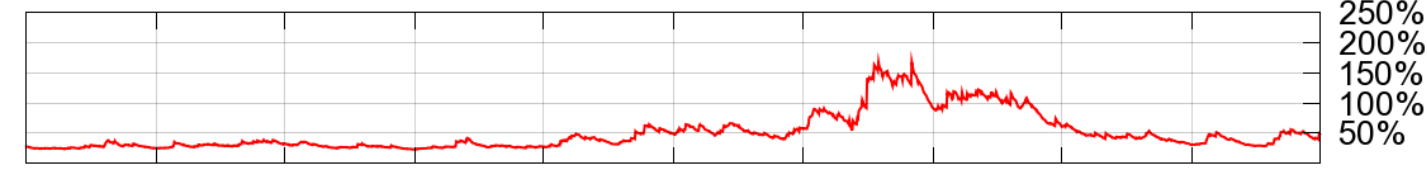
Jul 05 Jan 06 Jul 06 Jan 07 Jul 07 Jan 08 Jul 08 Jan 09 Jul 09 Jan 10 Jul 10

Figure 2: Average volatility by financial industry group.

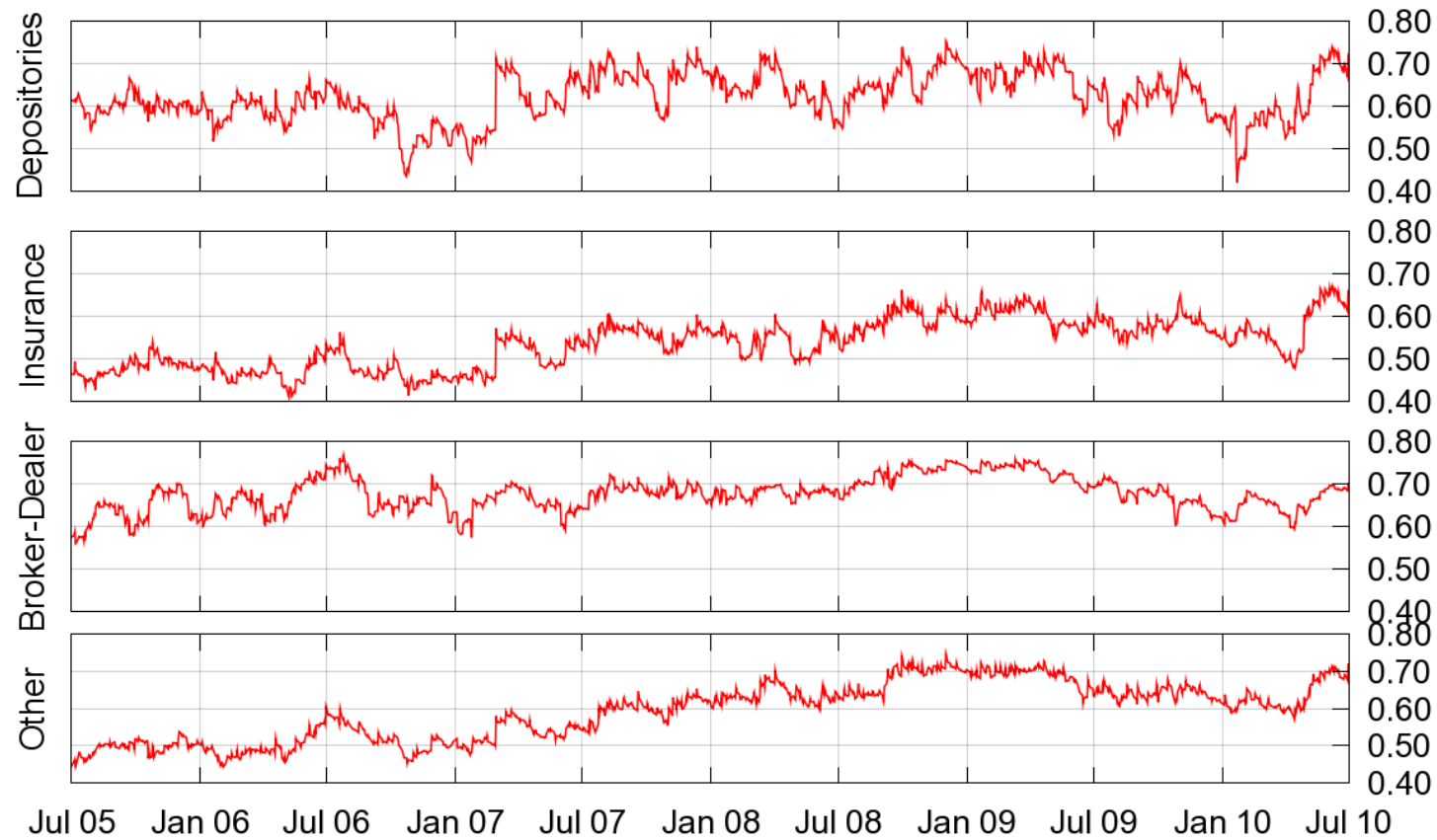

Figure 3: Average correlation by financial industry group. 

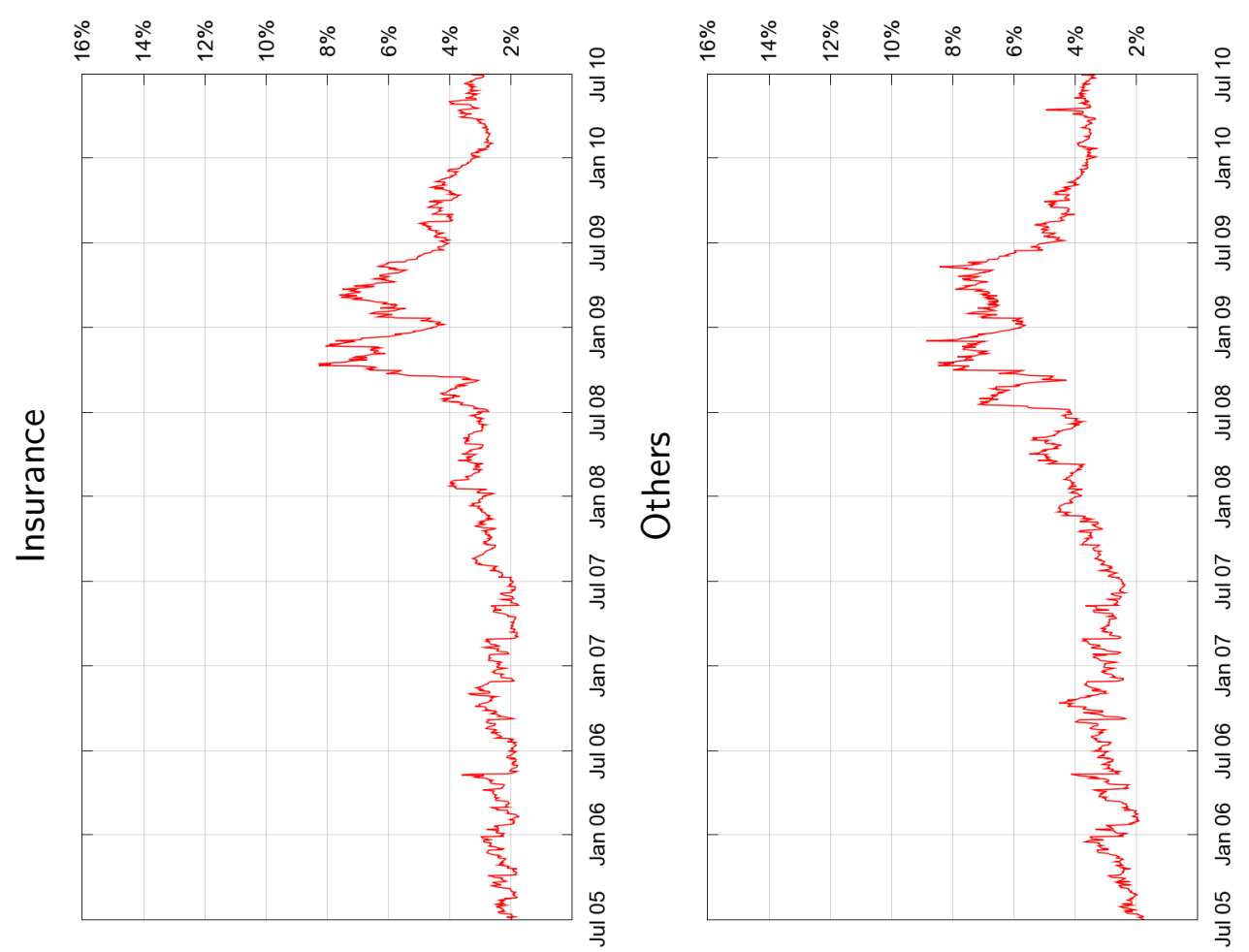

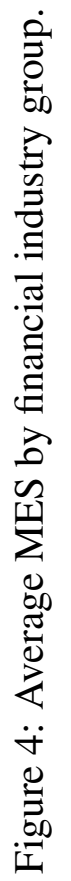
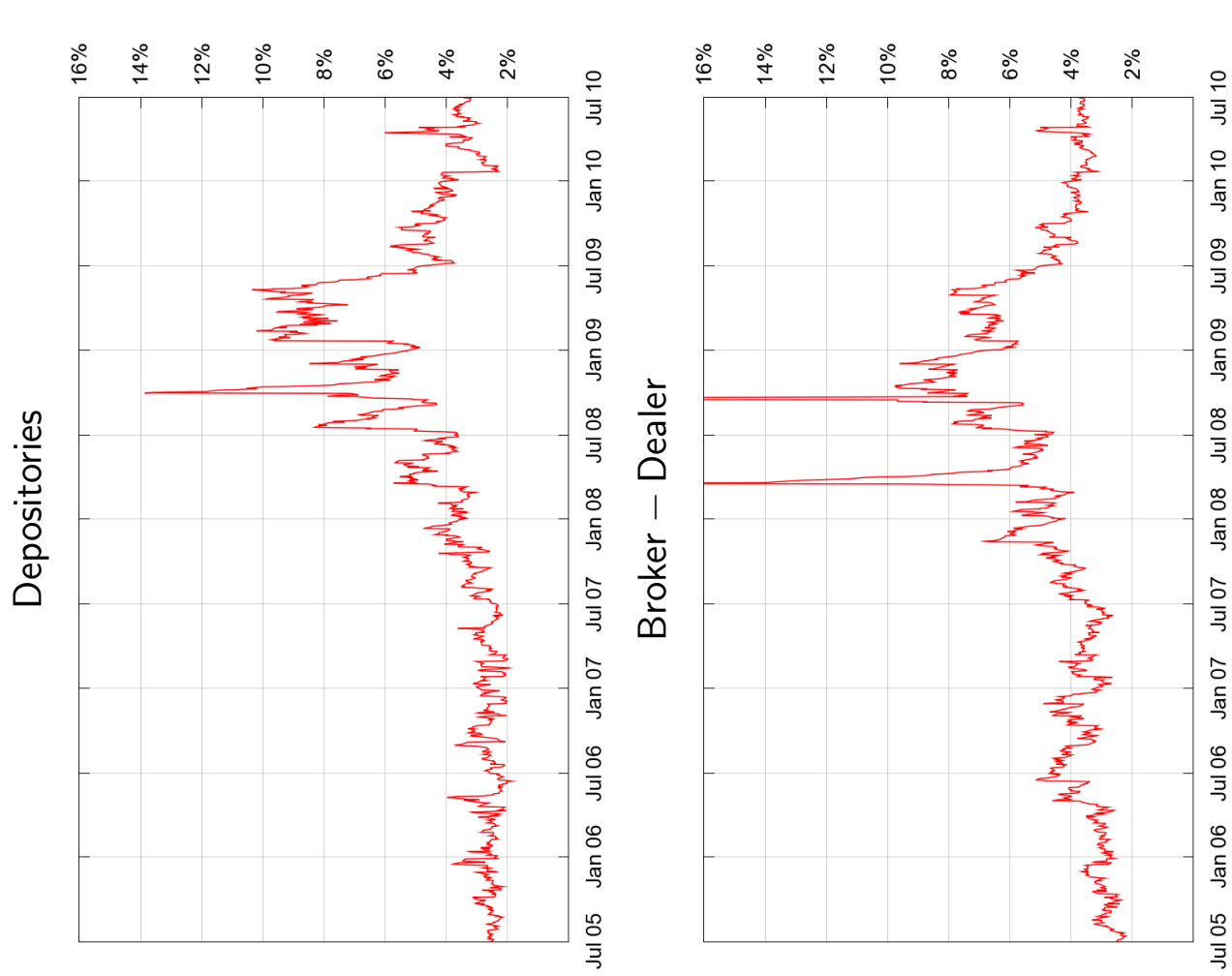


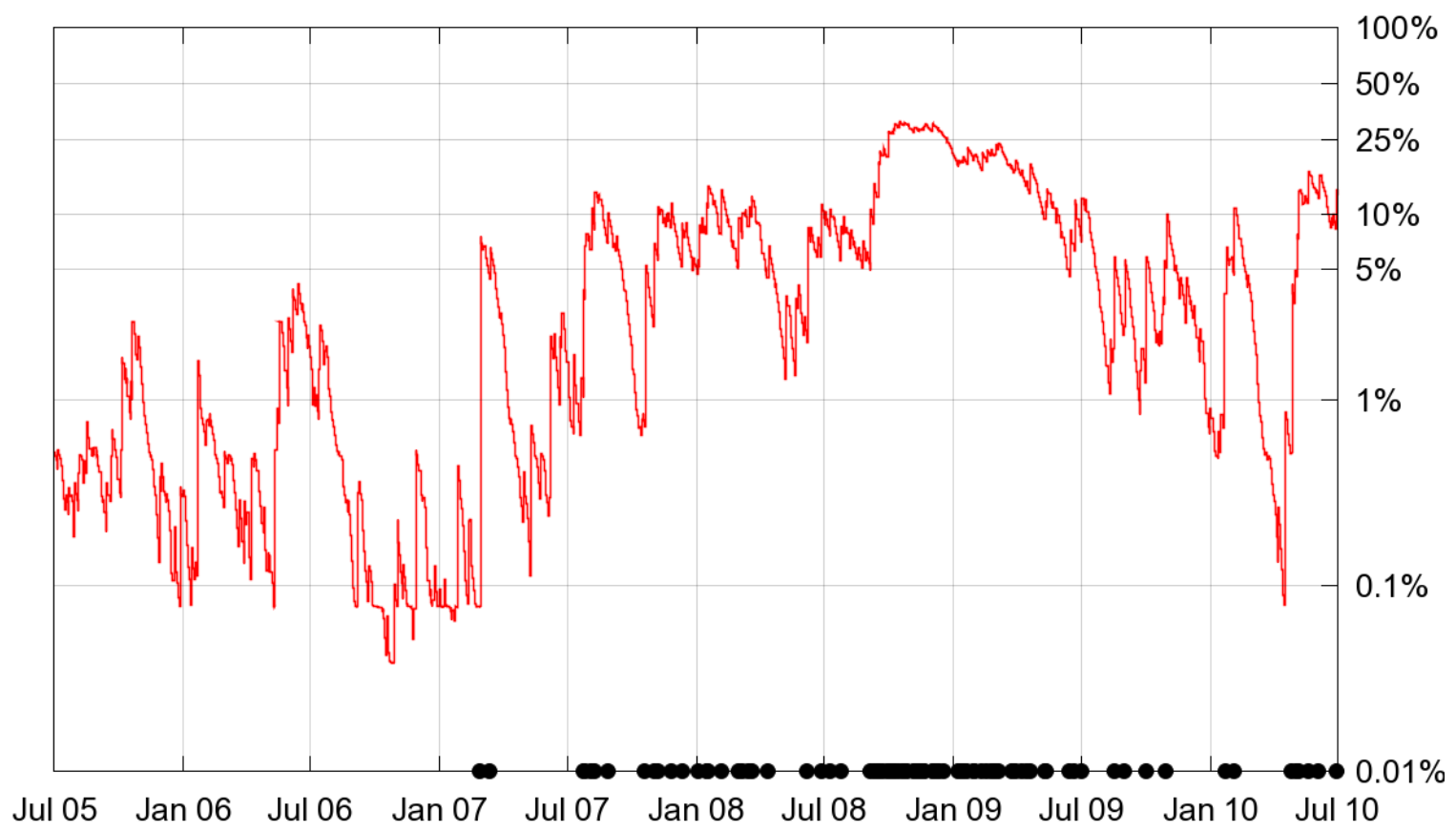

Figure 5: 1-step-ahead probability of a daily $2 \%$ loss in the market.

the begin of market rally, the level of volatility is roughly the same of 2007 . The all groups progressively cool down until May 2010, when news concerning the European sovereign debt crisis produce a new, yet moderate, surge in volatility. While the overall volatility trend is similar across groups the average differs, with Broker-Dealers and the Others being the most volatile groups. Most of the extreme volatility spikes in the series can be associated with well known distress days in the financial industry. For instance, Depositories have a spike around 200\% corresponding to the bankruptcy of Washington Mutual (September 2008) and Broker-Dealers go beyond 200\% with the acquisition of Bears Sterns (March 2008) and the bankruptcy of Lehman (September 2008).

Figure 3 shows correlation averages by industry group. Again, over all, the time series pattern is similar across sectors although there are some differences between Broker-Dealers and the other three groups. Correlations in the pre crisis period are moderatly high and in the range of 0.40 to 0.70 . The so-called Chinese correction of February 29, sharply shifts average 
correlations upwards for all sectors, with the biggest increase in dependence for commercial banks. As the financial crisis unwinds, correlation further levitate, going beyond 0.75 for Depositories and investment banks in December 2008. Once more, the average levels of correlation differ across groups. In post crisis period, correlations begin to decrease until in May 2010 when we observe a steep increase in dependence in conjunction with the surge of volatility. Broker-Dealers are always the most correlated sector, Insurance the least and Depositories together with the Other group lie in the middle.

We finally turn to the analysis of short turn MES and the probability of a systemic event. Figure 4 reports the average level of MES by industry group. In the pre crisis period, the levels of MES appear to be roughly similiar. The series start to increase from July 2007, reaching their peaks in December 2008. Depositories reach a MES of roughly 7\% and go beyond $10 \%$ at the end of September 2008, in conjunction with the bankruptcy of Washington Mutual. Broker-Dealers on the other hand have the biggest increase in mid March 2008 and mid September 2008 with the acquisition of Bears Sterns and liquidation of Lehman. MES starts to drop only after March 2009 and by January 2010 is back to its pre crisis levels. The european sovereign debt crisis does increase the level of MES but its impact is moderate. Interestingly, MES ranking of the industry groups has been highly consistent in time: BrokerDealers are the most systemically risky group followed by the Others group, Depositories and Insurance. We also report in Figure 5 the time varying probability of observing the systemic event $\left\{r_{m t}<C\right\}$. The rug plot displays the actual days on which a systemic event is observed. The probability of a systemic event is a function of the market volatility and the series exhibits the same time series pattern, with high probabilities in correspondence to the early peak of the financial crisis and the european sovereign debt crisis.

The inspection of residual diagnostics signals that the specification adequately fits the data. Here, we report residual diagnostics on the GARCH-DCC residuals series $\left(\hat{\epsilon}_{m t}, \hat{\xi}_{i t}\right)$. In particular, we focus on assessing the degree of dependence in the lower tails of the two innovations. In order to do this, we analysis the Hit $t_{t}$ variable constructed as follows: we first 


\begin{tabular}{|lcc|}
\hline & Avg. Hit. Violation & 10\% \\
\hline \hline D & 0.01310 & 0.31034 \\
I & 0.01277 & 0.37500 \\
BD & 0.01201 & 0.30000 \\
O & 0.01213 & 0.08696 \\
\hline
\end{tabular}

Table 4: Residuals Diagnostics.

\begin{tabular}{|l|ccc|}
\hline & GARCH/DCC/NP & Historical & Static Factor \\
\hline \hline RMSE & 0.0330 & 0.0370 & 0.0371 \\
RB & 1.1441 & 1.2204 & 1.2625 \\
RC & 0.4847 & 0.4702 & 0.4592 \\
DG & 0.1027 & 0.1775 & 0.1923 \\
\hline
\end{tabular}

Table 5: Short term MES forecasting.

transform the residual series $\left(\hat{\epsilon}_{m t}, \hat{\xi}_{m t}\right)$ into their ranks and then construct the Hit $\mathrm{H}_{t}$ variable as a dummy indicator which is one when both residuals on period $t$ are simultaneously below their $10 \%$ rank. Under the null of correct specification and absence of tail dependence, the sequence of hits behaves as an iid Bernoulli sequence with $p=1 \%$, and we can then use this to construct tests in the same spirit of Christoffersen (1998), Engle and Manganelli (2004) and Patton (2002). We perform a binomial test, where the null of the test is that the hit sequence is generated by a Bernoulli with $p=1 \%$. Table 4 reports the average of the Hit variable together with the percentage of rejected tests at at $1 \%$ level by industry group. The average hit is almost always systematically higher than the null of $1 \%$, however the deviation appears to be mild and in fact the binomial test is non significant in the majority of cases. Over all, results indicate that although the performance of the GARCH-DCC approach is satisfactory. There is some evidence of neglected lower tail dependence which might turn out to be quite important for MES forecasting. 


\subsection{Short Term MES Prediction and Evaluation}

In this section we carry out a short term MES forecasting exercise to get insights on the ability of our specification to model appropriately the data dynamics. We compare the predictive ability of our specification against two simple benchmarks. The first one is the MES estimator proposed in Acharya et al. (2010), which we label as "Historical", defined as

$$
\operatorname{MES}_{i t}^{1 \text { his }}(C) \equiv \frac{\sum_{\tau=t-W}^{t-1} r_{i \tau} I\left(r_{m \tau}<C\right)}{\sum_{\tau=t-W}^{t-1} I\left(r_{m \tau}<C\right)}
$$

that is the average of firm returns on event days over a given window of most recent observations (we use $W=4$ years). It is inspired by the risk management practice where rolling averages are often used to obtain estimates of ES or VaR. The second MES estimator is the one implied by assuming that firm returns are generated by a simple static factor model, i.e.

$$
r_{i t}=\beta_{i} r_{m t}+\epsilon_{i t}
$$

The "Static Factor" MES benchmark is then defined as

$$
\operatorname{MES}_{i t}^{1 \text { sf }}(C) \equiv \hat{\beta}_{i} \widehat{E S}_{m}(C)
$$

where $\hat{\beta}_{i}$ is the least square estimator of the factor loading and $\widehat{E S}_{m}(C)$ is the historical estimator of the ES of the market. Both statistics are computed using a rolling window estimation scheme using the last 4 years of data available.

We introduce a number of different metrics to evaluate forecasts. All metrics evaluate predictive ability by comparing on event days (i.e, when $r_{m t}<C$ ) the predicted MES with the realised losses, that is

$$
\operatorname{MES}_{i t}(C) \text { and } L_{i t}=-r_{i t} I\left\{r_{i t}<C\right\} \text {, }
$$


and we summarise forecasting ability along three dimensions: average loss, loss rankings and loss concentration.

The first prediction metric measures the discrepancy between the average loss of the firms an the predicted one. Let

$$
\widehat{\bar{L}}_{t}=\frac{1}{I} \sum_{i=1}^{I} \operatorname{MES}_{i t}(C) \quad \text { and } \quad \bar{L}_{t}=\frac{1}{I} \sum_{i=1}^{I} L_{i t}
$$

denote the predicted and actual average loss. We compute the Root Mean Square Error (RMSE) and Relative Bias (RB) of the predictions as

$$
R M S E=\sqrt{\sum\left(\widehat{\bar{L}}_{t}-\bar{L}_{t}\right)^{2}}
$$

and

$$
R B=\sum\left(\widehat{\bar{L}}_{t} / \bar{L}_{t}\right)
$$

In the context of systemic risk analysis it is also of interest to compute the relative Bias of predictions to measure how much average losses are being over or under predicted.

The rank correlation between MES prediction and the actual losses is the second evaluation metric we propose. Apart from the ability to produce accurate forecasts of the system average losses, MES predictions could also be of great interest if able to successfully rank firms according to the severity of the individual loss contributions. The Rank Correlation (RC) is computed as the Pearson correlation coefficient between ranks, that is

$$
R C_{t}=\frac{\sum\left(R_{i}^{L}-\bar{y}^{L}\right)\left(R_{i}^{\mathrm{MES}}-\bar{R}^{\mathrm{MES}}\right)}{\sqrt{\sum\left(R_{i}^{L}-\bar{y}^{L}\right) \sum\left(R_{i}^{\mathrm{MES}}-\bar{R}^{\mathrm{MES}}\right)}}
$$

where $R_{i t}^{L}$ and $R_{i t}^{\mathrm{MES}}$ are the loss and MES ranks for firm $i$. We denote the average rank correlation by $R C$.

Lastly, we want to compare the predicted and actual level of dispersion of losses in the 
financial system. We are interested in predicting what is the share of the total losses generated by, say, the top $10 \%$ distressed firms, and compare it with the actual one. This can readily be done using the Gini dispersion coefficient

$$
G_{t}=1-\frac{2}{I-1}\left(I-\frac{\sum_{i \in I} i L_{(i) t}}{\sum_{i \in I} L_{(i) t}}\right) \quad \text { and } \quad \widehat{G}_{t}=1-\frac{2}{I-1}\left(I-\frac{\sum_{i \in I} i \operatorname{MES}_{(i) t}}{\sum_{i \in I} \operatorname{MES}_{(i) t}}\right)
$$

where $L_{(i) t}^{C}$ and $\operatorname{MES}(C)_{(i) t}$ denote the series of losses and MES on day $t$ sorted in ascending order. We use $D G$ to denote the average difference between the predicted and actual concentration.

The forecasting exercises is implemented as follows. Starting from July 2005 we compute 1 period ahead MES predictions conditionally on a $2 \%$ market drop and use the realizations observed on the event days $r_{m t}<-2 \%$ to compute the prediction losses. The parameter estimates needed to produce forecasts from the GARCH/DCC/Nonparametric approach are updated once a week on the last weekday.

Figures 6 reports the summary plots of the Short term MES forecasts. There are 76 event days in between July 2005 and July 2010, most of which are concentrated in between the end of 2008 and the beginning of 2009. The average losses are typicall between $2 \%$ and $5 \%$ but at the peak of the crisis they can be as high as $20 \%$. The time series profile of the average losses is, of course, the one of volatility. MES does not appear to track the average losses to well during the peak of the crisis, where forecasts are often underestimating the losses. Rank correlation of losses and MES is dispersed between 0 and 0.90 and appears to be substantially stable in time and quite high on average. The concentration of losses ranges from 20 to 70 and it has been well tracked by the MES predictions although it seems to underestimate. Interestingly, at the peak of the crisis the concetration of losses is higher then what is otherwise observed.

Table 5 reports summary statistics of the short term MES forecasts against the benchmarks. All metrics show that the dynamic approach we propose performs better. From an 
average loss point of view however, all methods underestimate the average losses in the crisis.

The bias is also found to be significant for all method by the Wilcoxon signed-rank test. Also, the mean difference in the predicted and actual concentration indices signal that the actual concentration of losses is higher than the predicted one. However this time, the difference is not judged to be signficant by the Wilcoxon signed-rank test.

\subsection{Long Run MES Prediction and Systemic Risk}

The forecasting exercise of the previous section shows the predictive ability of our model in forecasting short term downside exposure to market shocks. While these forecasts give important signals, they are of limited use from a systemic risk measurement perspective. Firstly, the horizon of interest of a regulator is generally speaking a long one and by construction short term measures give greater importance to recent shocks rather than long run dynamics. Secondly, following the Acharya et al. (2010) framework, MES alone does not convey which firms are big systemic risk contributors. To overcome these limitations, in this section we forecast a long run MES forecasting to compute the SRISK index proposed in Section 2

We design our long run forecasting methodology as follows. At the end of each month starting from July 2005, we estimate our specification for each firm in the panel that has been trading for at least 2 years. Using the simulation based procedure described in Section 3, we compute the long run MES of each firm and ES of the market conditionally on a market drop of $40 \%$ over the following six months, as well as the time varying probability of the systemic event PoS. Using debt and equity data we then compute the expected capital shortfall and the SRISK measures. Finally, we use SRISK to construct rankings of the top ten systemically risky institutions. Note that our methodology allows one to compute daily rankings and we chose a monthly update frequency only to reduce the computational burden. In the computation of the expected capital shortfall, debt is proxied with its book value, equity is proxied 
with market value of equity and the prudential ratio $k$ is set to $8 \%$.

The long run predictions of PoS and ES give insights on the model implied views on the long run risks of the economy. Figure 7 shows the two series between 2005 and 2010. In the pre crisis period, the level of PoS is moderately low, being roughly $0.1 \%$. However, starting from 2007 the probability escalates rather steeply and by the end of the year it is increased by 10 times. PoS reaches its peak at $10 \%$ after the Lehman bankruptcy and it then decreases and stabilizes around 1\% starting from mid 2009. The ES ranges between $45 \%$ and $50 \%$ until the Lehman bankruptcy where it spikes up to almost 60\%, implying at the end of the fall of 2008 a crisis is not just more likely but also more severe. ES then regresses to a lower level and by mid 2010 is approximately $50 \%$.

Long run MES and CS show the exposure and capital shortage of an individual firm to be expected in case of a systemic event. Rather than looking at industry averages, it is interesting to look at individual firm results. In Figure 8 we report the results of a representative firm from each group: Citigroup, AIG, Lehman and Fannie. Of course, the Lehman and Fannie series are interrupted in September 2009. Over all, all long run MES predictions display a similar time trend. MES starts increasing from January 2007, it peaks at the end of 2008/beginning of 2009 and then declines and stabilizes at lower levels that, however, are still higher than those observed in the pre crisis period. The actual peak of the series differs from firm to firm: some firms peak in September 2009 while others in February 2010, before the beginning of the market recovery. The capital shortfall estimates give some interesting insights on the shortage dynamics in this period. In the pre-crisis period Lehman and Fannie have a large capital shortfall while Citigroup and AIG are appropriately capitalized (they have a negative shortage, that is they have enough capital in case of a crisis). Starting from January 2007 capital shortfall begins to quickly deteriorate. Before Lehman files for bankruptcy and Fannie is place under conservatorship in September 2009, their capital shortage have, respectively, quintupled and almost tripled with respect to the initial levels. Citigroup and AIG also have a sharp increase in capital shortage which is particularly severe for Citigroup, which by January 
2008 exceeds 100 USD billions.

The aggregate SRISK summarises the capital shortage dynamics in the whole system. It is defined as the sum of all the positive capital shortfalls of all firms and its plot is displayed in Figure 9. In the pre crisis period the total shortfall is estimated to be around 200 USD billions. This figure rapidly escalates starting from 2007 and starting from January 2008 is already tripled. The series reaches of 900 USD billions as a result of the Lehman bankruptcy and starts decreasing only with the start of the market rally in March 2009. As of July 2010 the system still looks like it has not fully recovered yet.

Finally, in Table 6 we report the rankings of the systemically risky U.S financial institutions. On eight pre selected dates we report the top 10 most risky institutions according to SRISK\% measure. At the beginning of 2007, when the total capital shortfall of the system is modest, the list contains mostly highly levered Broker-Dealers firms together with Freddie and Fannie. As the crisis unwinds, large commercial banks start rising up in the top ten, like Citigroup, Bank of America and JP Morgan. It is interesting to note that as of July 2007, approximately 1 year and 3 months before the Lehman bankruptcy, 8 firms out of the SRISK top 10 are all institutions that in different ways have been severely hit by the crisis and that have produce negative externalities to the economy.

\section{Conclusion}

The 2007/2009 financial crisis calls for a better understanding of systemic risk. In this paper we propose a systemic risk index called SRISK which measure the expected capital shortfall of a financial institution in a crisis. Following Acharya et al. (2010), capital shortfall in a crisis measures systemic risk in that such shortage is going to generate a negative externalities to the whole economy. The argument is that an institution in distress when the economy is already in distress, cannot be taken over by the rest of the system and the government faces the question of whether to rescue the firm with taxpayer money as other avenues are no 


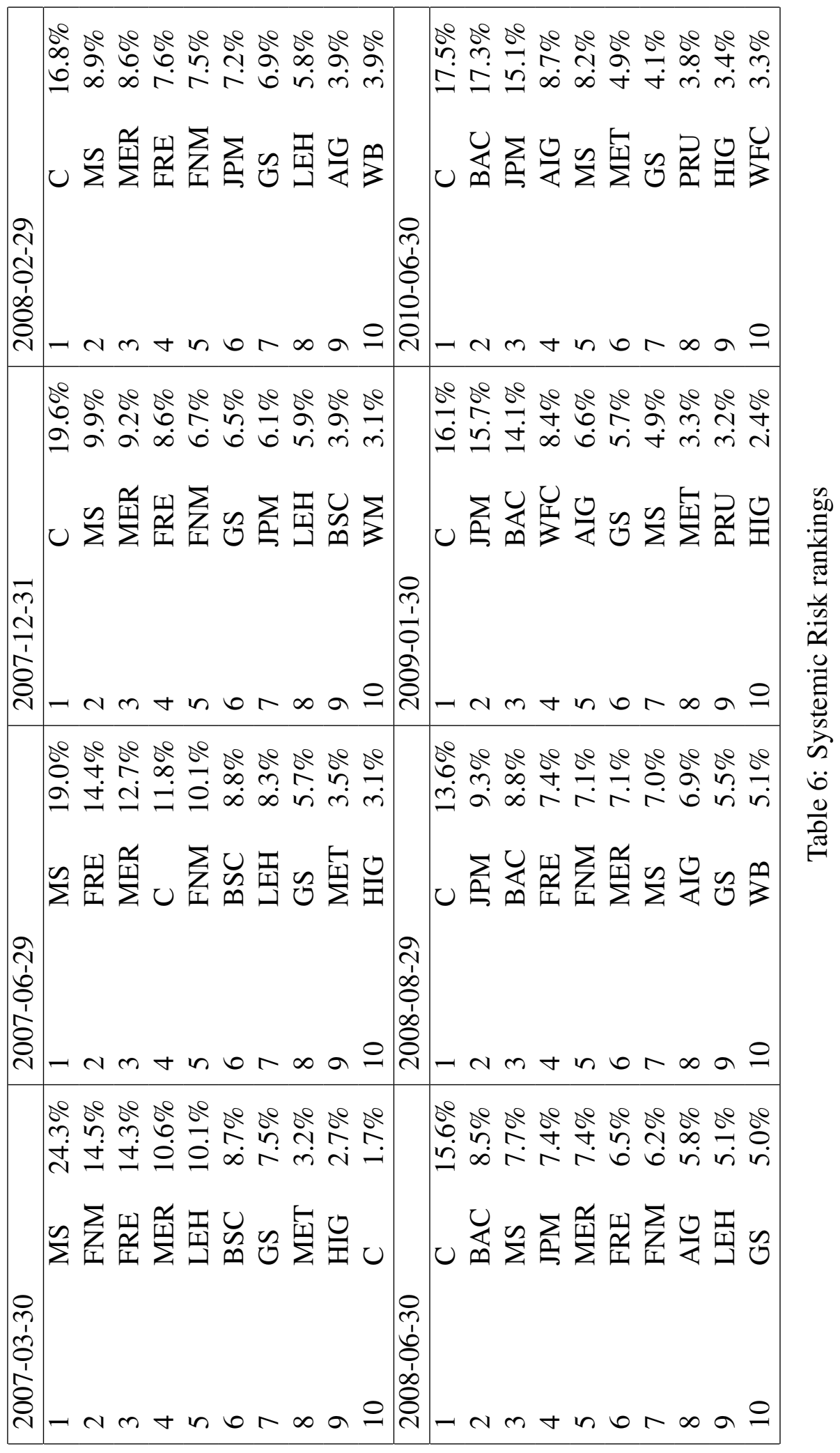


longer available. SRISK is a function of the level of leverage of the firm and MES, the tail expectation of the firm equity returns conditionally on a substantial loss in the market. While the leverage of a firm can be measured using balance sheet data, MES requires appropriate time series methodology. We develop an econometric model for the bivariate firm and market return which decomposes the dynamics of the pairs in terms of time varying volatility, correlation and possibly nonlinearly dependent innovation shocks. The model allows one to easilly construct one and multi period ahead MES predictions. We analyse the systemic risk of top U.S. financial firms between 2005 and 2010. Results shows that despite the fact that the levels of MES reached in the Fall of 2008 are rather extreme by historical standards, the ranking of systemically risky industry groups has been substantially stable over time. The analysis shows that the most systematically risky sectors are the Broker-Dealers and the Other groups, which indeed do contain many of the companies more severely hit by the crisis. MES analysis provides useful tools for monitoring systemic risk and, in retrospective, it captures several of the early signs of the financial crisis.

\section{References}

Acharya, V., , Pedersen, L., Philippe, T., and Richardson, M. (2010). Measuring systemic risk. Technical report, Department of Finance, NYU.

Adrian, T. and Brunnermeier, M. K. (2009). CoVaR. Technical report, FRB of New York. Staff Report No. 348.

Aielli, G. (2006). Dynamic conditional correlations: On properties and estimation. Technical report, Department of Statistics, University of Florence.

Aielli, G. (2009). Dynamic conditional correlations: On properties and estimation. Technical report, Department of Statistics, University of Florence. 
Allen, L., Bali, T. G., and Tang, Y. (2010). Does systemic risk in the financial sector predict futur economic downturns? Technical report.

Billio, M., Getmansky, M., Lo, A. W., and Pellizzon, L. (2010). Econometric measures of systemic risk in the finance and insurance sectors. Technical report.

Bollerslev, T. (2008). Glossary to arch (garch). Technical report, Glossary to ARCH (GARCH). Research Paper 2008-49.

Brownlees, C. T. (2011). On the relation between firm characteristics and volatility dynamics with an application to the 2007-2009 financial crisis. Technical report.

Caporin, M. and De Magistris, P. S. (2010). On the evaluation of marginal expected shortfall. Technical report.

Christoffersen, P. F. (1998). Evaluation of interval forecasts. International Economic Review, 39, 841-862.

Ding, Z. and Engle, R. (2001). Large scale conditional covariance matrix modeling, estimation and testing. Technical report, NYU Stern School of Business. Working Paper FIN-01-029.

Engle, R. (2002a). Dynamic conditional correlation: A simple class of multivariate generalized autoregressive conditional heteroskedasticity models. Journal of Business \& Economic Statistics, 20(3), 339-350.

Engle, R. (2009). Anticipating correlations: a new paradigm for risk management. Princeton University Press.

Engle, R. and Manganelli, S. (2004). Asset allocation by variance sensitivity analysis. Journal of Business and Economic Statistics, 22, 367-381. 
Engle, R. and Sheppard, K. (2001). Theoretical and empirical properties of dynamic conditional correlation multivariate garch. Technical report, NBER. Working Paper No. W8554.

Engle, R., Shephard, N., and Sheppard, K. (2009). Fitting vast dimensional time-varying covariance models. Technical report, NYU. Working Paper No. FIN-08-009.

Engle, R. F. (2002b). New frontiers for ARCH models. Journal of Applied Econometrics, 17, 425-446.

Glosten, L. R., Jagananthan, R., and Runkle, D. E. (1993). On the relation between the expected value and the volatility of the nominal excess return on stocks. The Journal of Finance, 48(5), 1779-1801.

Hautsch, N., Schaumburg, J., and Schienle, M. (2010). Quantifying time-varying marginal systemic risk contributions. Technical report.

Manganelli, S., Kim, T.-H., and White, H. (2010). Var for var: Measuring systemic risk using multivariate regression quantiles. Technical report.

Mezrich, J. and Engle, R. F. (1996). GARCH for groups. Risk, 9, 36-40.

Rabemananjara, R. and Zakoïan, J. M. (1993). Threshold ARCH models and asymmetries in volatility. Journal of Applied Econometrics, 8(1), 31-49.

Scaillet, O. (2005). Nonparametric estimation of conditional expected shortfall. Insurance and Risk Management Journal, 74, 639-660.

Schwaab, B., Koopman, S.-J., and Lucas, A. (2011). Systemic risk diagnostics, coincident indicators and early warning signals. Technical report.

Taylor, J. W. (2008). Using exponentially weighted quantile regression to estimate value at risk and expected shortfall. Journal of Financial Econometric, 6, 382-406. 


\section{AverageLoss}

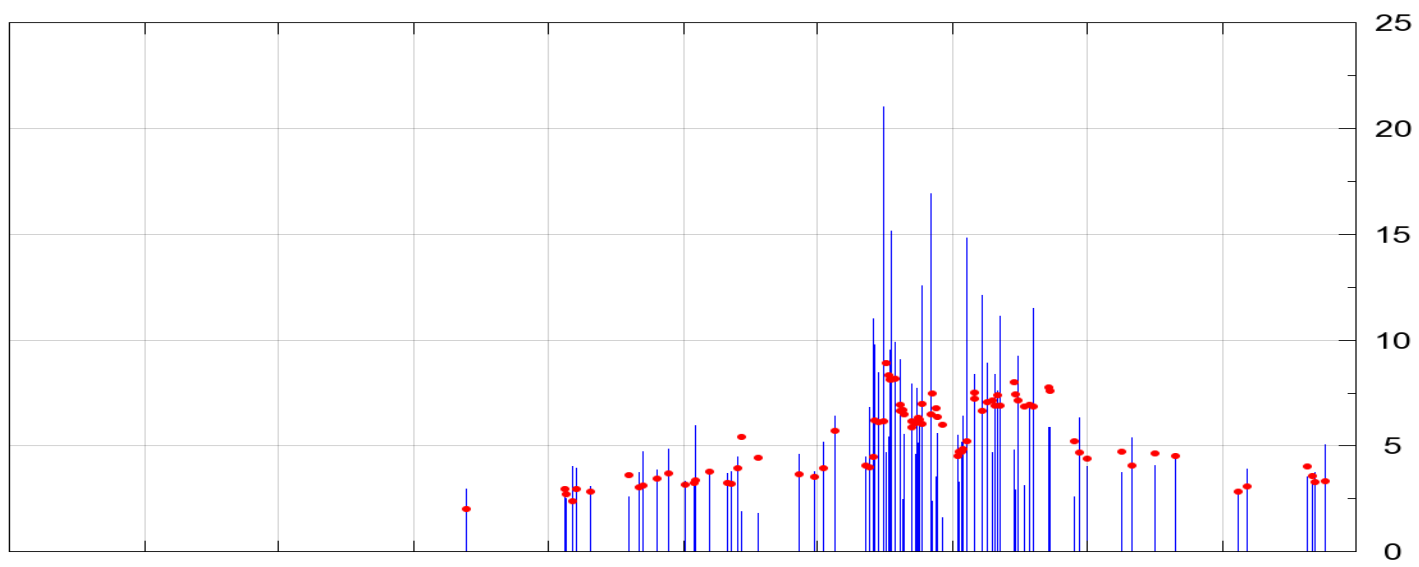

2005-07 2006-01 2006-07 2007-01 2007-07 2008-01 2008-07 2009-01 2009-07 2010-01 2010-07

\section{LossRanks}

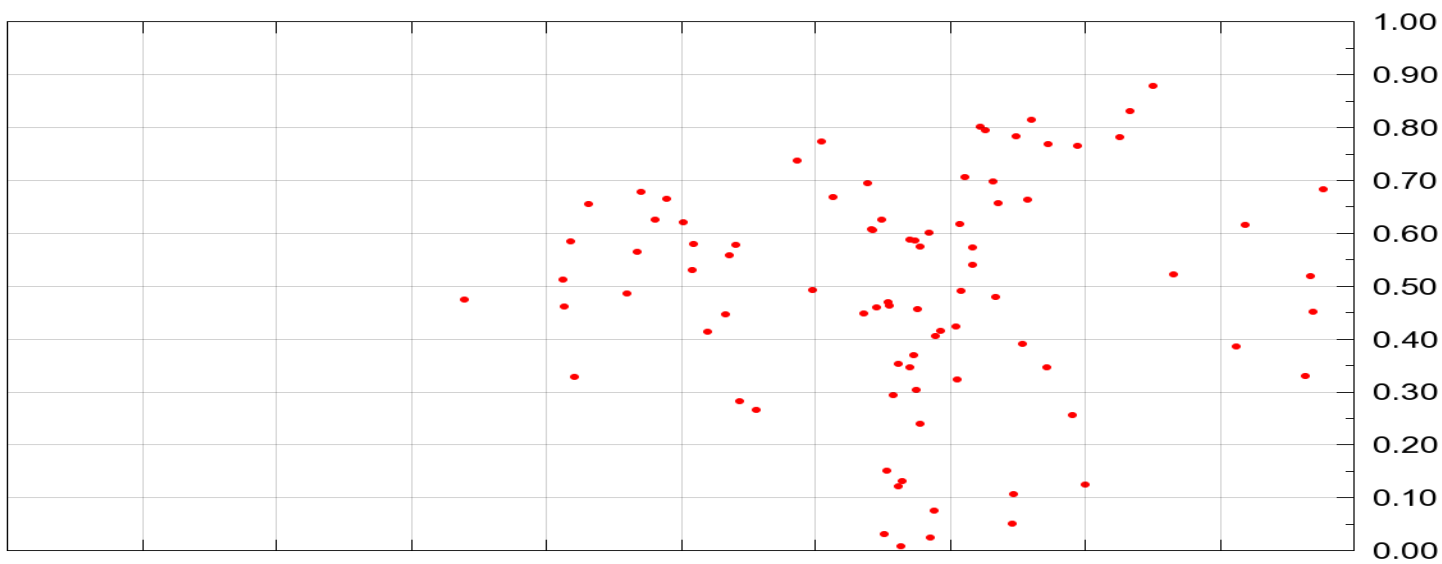
2005-07 2006-01 2006-07 2007-01 2007-07 2008-01 2008-07 2009-01 2009-07 2010-01 2010-07

\section{LossConcentration}

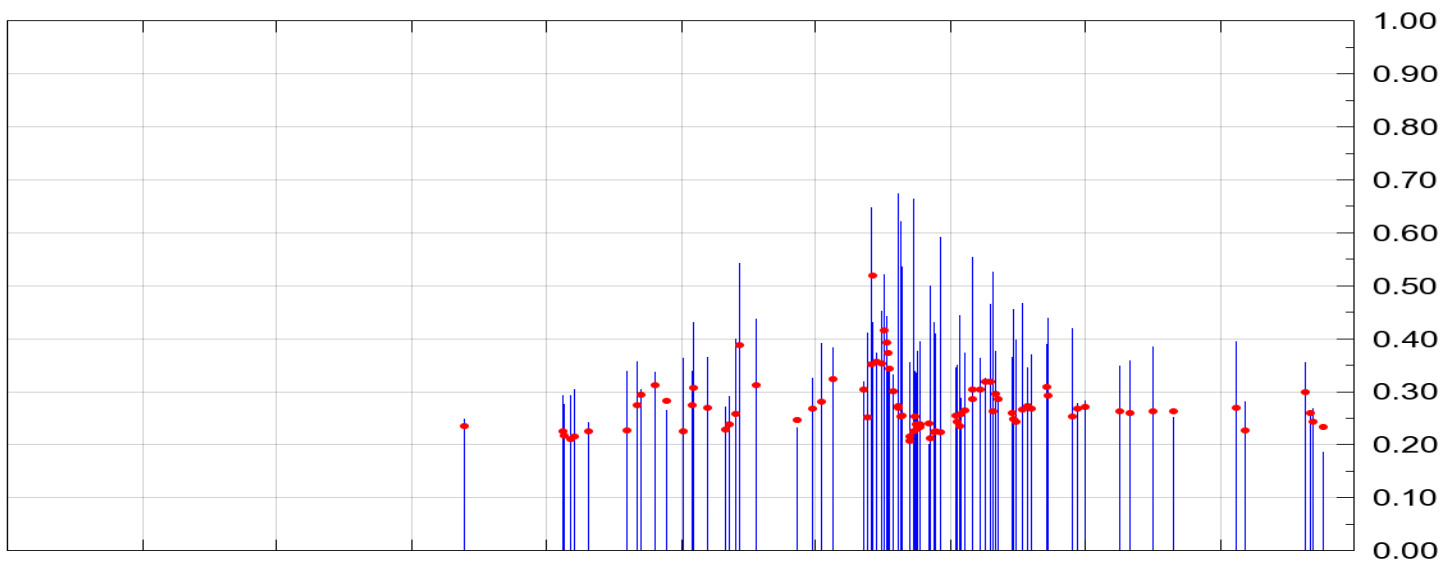
2005-07 2006-01 2006-07 2007-01 2007-07 2008-01 2008-07 2009-01 2009-07 2010-01 2010-07

Figure 6: 1 day ahead forecasting performance 1995-2008. 
PoS

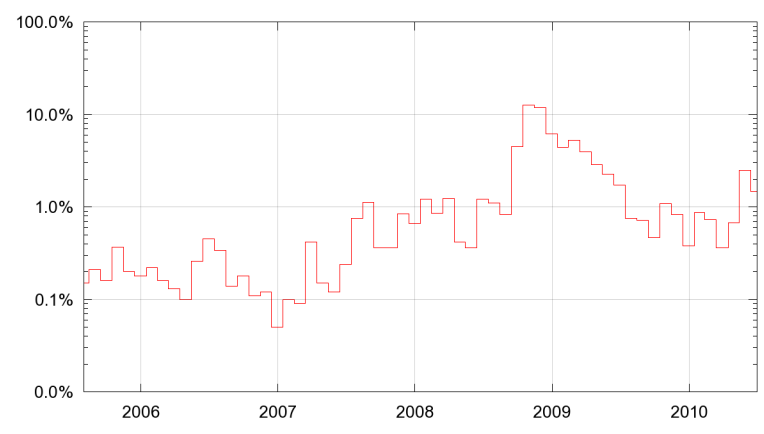

ES

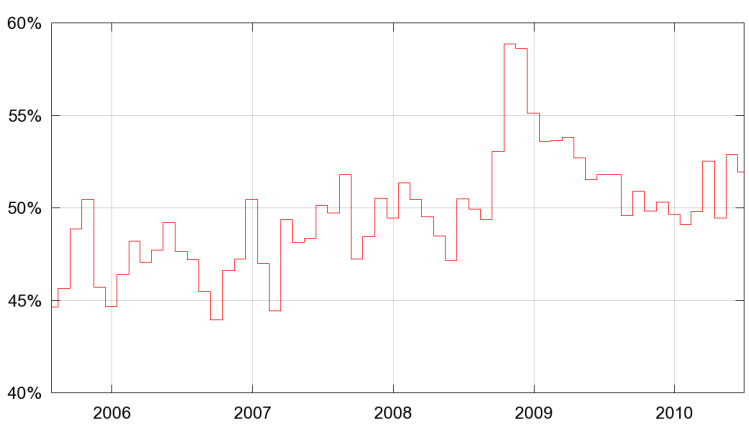

Figure 7: Long run probability of a systemic event (PoS) and Expected Shortfall (ES) predictions.
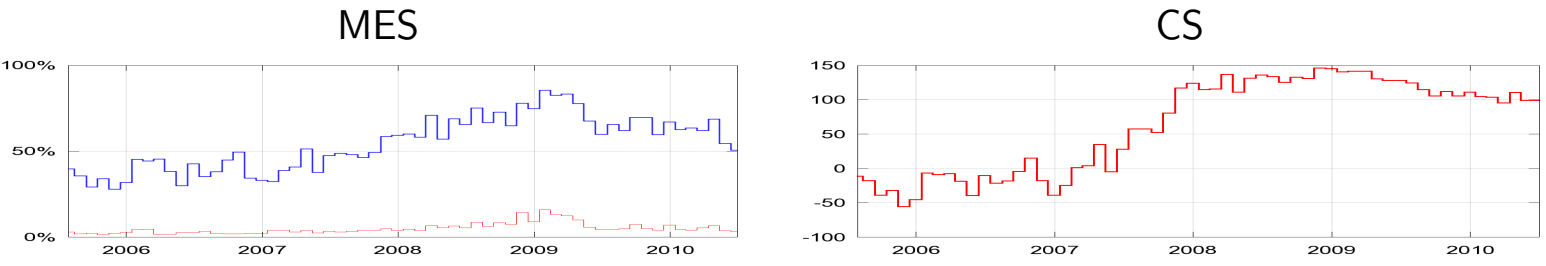

C
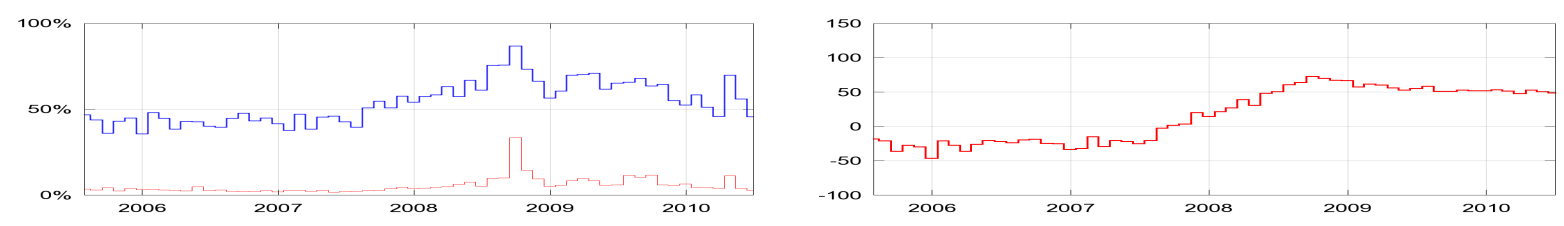

AIG
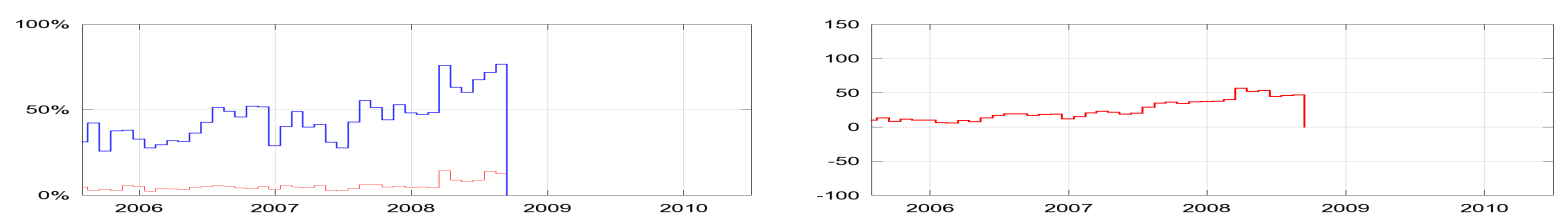

\section{LEH}
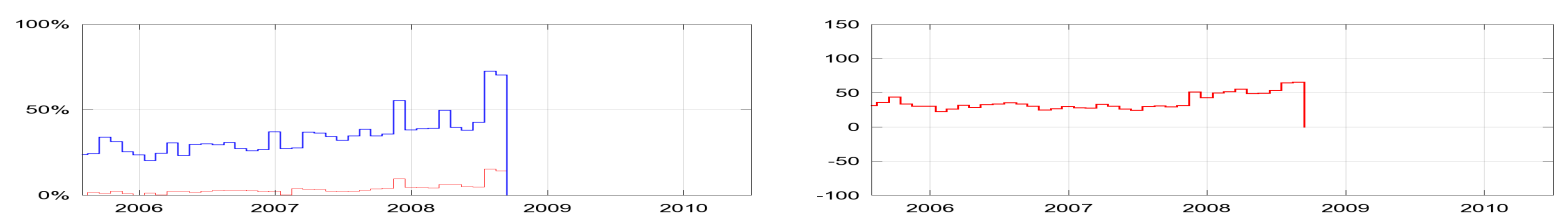

FNM

Figure 8: Long run MES predictions and Expected Capital Shortfall CS. 


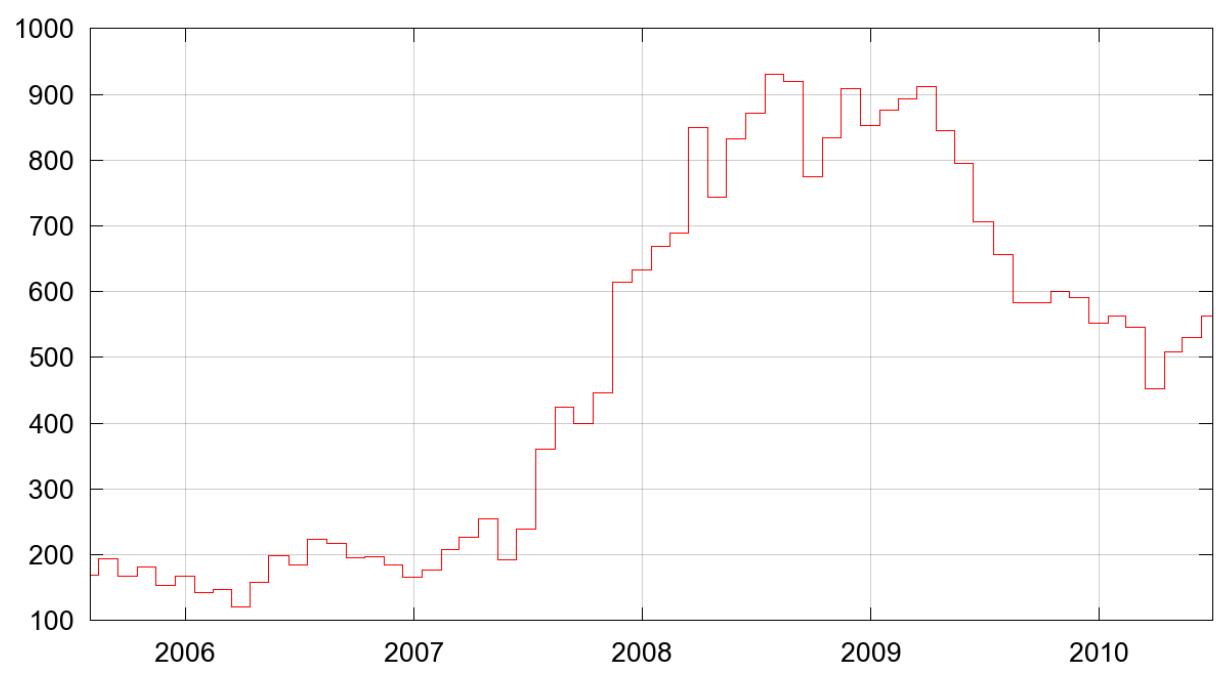

Figure 9: Aggregate SRISK of the top U.S. financial institutions. 